\title{
Actualización del Consenso "Neumonía asociada a ventilación mecánica" Primera parte. Aspectos diagnósticos
}

\author{
Alberto Fica C., Marcela Cifuentes D. y Béatrice Hervé E. en representación del Comité de \\ Infecciones Intrahospitalarias. Sociedad Chilena de Infectología
}

\begin{abstract}
Hospital Militar de Santiago, Chile. Servicio de Infectología y Unidad de Infecciones Intrahospitalarias (AFC). Hospital Clínico de la Universidad de Chile. Comité de Infecciones Intrahospitalarias (MCD).

Clínica Las Condes, Santiago, Chile.
\end{abstract} Laboratorio de Microbiología (BHE).

Documento elaborado por el Grupo de Trabajo sobre Diagnóstico de Neumonía Asociada a Ventilación Mecánica.

(Presentado en parte en el XXVI Congreso Chileno de Infectología, Viña del Mar, octubre de 2009).

Conflicto de interés: ninguno. Fuente de financiamiento: ninguna.

Recibido: 25 de abril de 2010

\section{Introducción}

$\mathrm{E}$ 1 año 2001, la Sociedad Chilena de Infectología elaboró una guía sobre Neumonía asociada a ventilación mecánica (NAVM) que contenía recomendaciones diagnósticas, terapéuticas y de prevención ${ }^{1-3}$. Este nuevo documento actualiza y reemplaza la revisión previa sobre problemas diagnósticos. Al igual que en la primera versión, los objetivos finales de este documento son:

- Entregar recomendaciones basadas en evidencia que permitan un diagnóstico racional de la NAVM.

- Facilitar la recolección de datos epidemiológicos y su comparación.

- Sugerir alternativas con factibilidad operativa y económica para nuestra realidad como país.

Las recomendaciones efectuadas fueron elaboradas por revisión de la literatura científica y la racionalidad de cada una de ellas es comentada específicamente en el texto y en las tablas de respaldo.
Desde la publicación previa han aparecido nuevos trabajos sobre estrategias diagnósticas microbiológicas, sobre agentes infecciosos emergentes, se ha acumulado información sobre bio-marcadores para el reconocimiento de pacientes sépticos en UCI, incluyendo aquellos con NAVM y ha emergido un nuevo concepto, la traqueobronquitis asociada a ventilación mecánica (TAVM).

Las recomendaciones finales se presentan de acuerdo a su nivel de evidencia y fuerza de recomendación, un aspecto no incluido el año 2001. El esquema utilizado fue el mismo utilizado en el Consenso nacional del paciente con neutropenia febril organizado por la Sociedad Chilena de Infectología, publicado el año 2005, el que se reproduce en la Tabla $1^{4}$.

El documento revisa en forma secuencial:

- Las limitaciones diagnósticas de los parámetros clínicos y radiológicos para el reconocimiento de la NAVM.

- Las estrategias diagnósticas validadas en la literatura con su impacto en morbimortalidad.

- El uso de bio-marcadores en el reconocimiento de NAVM. 
- El concepto de TAVM.

- Aspectos diagnósticos de NAVM en pediatría.

En la parte final se presentan las recomendaciones de este grupo de trabajo incluyendo una sección específica sobre agentes patógenos en NAVM. En un anexo se incluyen los protocolos de trabajo microbiológico y las recomendaciones sobre el informe del laboratorio.

\section{Antecedentes generales}

La NAVM es una complicación que ocurre en alrededor de 20 a $25 \%$ de los pacientes en ventilación mecánica (VM) por más de 48 horas, con una incidencia de 3\% al día durante los primeros 5 días, $2 \%$ entre el quinto y décimo día y $1 \%$ adicional, diariamente, de allí en adelante ${ }^{5,6}$. Se ha estimado que el riesgo de tener neumonía es 21 veces mayor en los pacientes en $\mathrm{VM}^{5}$. La mortalidad adicional que provoca la NAVM, o mortalidad atribuible ha sido estudiada observándose un amplio rango que va desde 30 a $70 \%$ según diferentes estudios ${ }^{5,6}$. Dichos reportes han demostrado que en los sobrevivientes se prolonga significativamente la estadía hospitalaria (4 a 13 días), aumenta el uso de antimicrobianos y se produce un incremento de los $\operatorname{costos}^{6,7}$. Representa, en incidencia, la primera o segunda causa de infecciones intrahospitalarias asociada a procedimientos invasores y la primera en letalidad ${ }^{6}$. Estas cifras enfatizan el impacto que la NAVM tiene en la morbilidad y mortalidad en estos pacientes. En NAVM, uno de los factores determinantes en el pronóstico favorable del paciente es el tratamiento antimicrobiano apropiado precoz ${ }^{8-10}$. Para ello es necesario contar con información epidemiológica sobre la microbiología de cada institución.

\section{Limitaciones en el diagnóstico de NAVM sobre bases clínicas y radiológicas}

Los criterios clínico-radiológicos establecidos por Johanson y cols, que incluyen infiltrados en la radiografía de tórax asociados al menos a dos de los siguientes signos: fiebre, leucocitosis o secreciones traqueo-bronquiales purulentas, son sensibles, pero no específicos para el reconocimiento de NAVM debido a la existencia de otras patologías de origen no infeccioso que se sobreponen con el mismo cuadro clínico ${ }^{11,12}$. Otras causas para este perfil incluyen la contusión pulmonar, hemorragia alveolar, embolia pulmonar, SDRA, tumor infiltrante, neumonitis actínica o reacciones de hipersensibilidad ${ }^{12}$. La especificidad limitada de los elementos clínicos y radiológicos (falsos positivos) determina un sobre-diagnóstico de NAVM y la exposición innecesaria a algún antimicrobiano.

Los criterios de Johanson y cols, mencionados más arriba, tienen una sensibilidad de $69 \%$ y una especifici- dad de $75 \%$, de acuerdo a estudios postmortem ${ }^{13}$. El uso combinado de todos los criterios clínicos mencionados y de las anormalidades radiológicas para el reconocimiento de NAVM logra aumentar la especificidad ( $>90 \%$ ) pero la sensibilidad disminuye notoriamente (a menos del $50 \%)^{13,14}$. Según la evidencia disponible, el diagnóstico clínico de NAVM está asociado a resultados falsos negativos en 30 a $35 \%$ de los casos por limitaciones en la sensibilidad y a falsos positivos entre 20 y $25 \%$ por limitaciones en la especificidad. En otras palabras, el uso exclusivo de los criterios clínicos de Johanson implica la exclusión de aproximadamente 1 de cada 3 casos de NAVM y el sobre-tratamiento de uno cada 4 a 5 casos sospechosos. Alternativamente, se podría decir que la aplicación de la información clínica y radiológica es más útil para descartar casos de NAVM que para su reconocimiento ${ }^{15}$.

La radiografía de tórax por si sola tiene una alta sensibilidad ( $>90 \%$ ) pero una especificidad limitada para el diagnóstico de NAVM $(<35 \%)^{13,16,17}$. El broncograma aéreo es el signo radiológico que tiene una mayor sensibilidad para el diagnóstico de NAVM, siempre y cuando sea múltiple (66\%). Sin embargo, su especificidad es limitada $(62 \%)$ y el valor predictor positivo es de sólo 51 a $60 \%{ }^{13,17}$. Otros signos con alta sensibilidad pero baja especificidad incluyen el borramiento de la silueta cardíaca y los infiltrados alveolares bilaterales ${ }^{17}$. Los signos radiológicos con alta especificidad, tales como el broncograma aéreo localizado o el abombamiento de una cisura $(95 \%)$, tienen una muy baja sensibilidad $(<$ $17 \%)^{17}$. En grupos especiales de pacientes, tales como los quirúrgicos, los infiltrados segmentarios o asimétricos tienen una mejor correlación con $\mathrm{NAVM}^{18}$. En pacientes

\begin{tabular}{|c|c|}
\hline $\begin{array}{l}\text { Grado de } \\
\text { recomendación }\end{array}$ & Definiciones \\
\hline A & Buena evidencia para recomendar su uso \\
\hline B & Moderada evidencia para recomendar su uso \\
\hline C & Pobre evidencia para recomendar su uso \\
\hline D & Moderada evidencia para desaconsejar su uso \\
\hline $\mathrm{E}$ & Buena evidencia para desaconsejar su uso \\
\hline $\begin{array}{c}\text { Calidad de la } \\
\text { evidencia }\end{array}$ & Clasificación \\
\hline 1 & Uno o más trabajos prospectivos randomizados y controlados \\
\hline 2 & $\begin{array}{l}\text { Uno o más estudios clínicos no randomizados; uno o más estudios de cohorte } \\
\text { o caso-control (idealmente multicéntrico); múltiples series de casos; o experi- } \\
\text { mentos no controlados con resultados significativos }\end{array}$ \\
\hline 3 & $\begin{array}{l}\text { Opiniones de expertos, basados en experiencias clínicas, estudios descriptivos } \\
\text { o reportes de comités }\end{array}$ \\
\hline
\end{tabular}


con SDRA, la dificultad diagnóstica es aún mayor. Se ha sugerido que la asimetría de imágenes en la radiografía es un marcador de $\mathrm{NAVM}^{19}$. Sin embargo, estudios de autopsias señalan que $30 \%$ de los pacientes con SDRA presentan asimetría en las radiografías ${ }^{20}$. Desde el punto de vista radiológico, los falsos negativos son poco frecuentes pero pueden presentarse en fases iniciales de NAVM, en pacientes con neutropenia o en casos de neumonía por Pneumocystis jiroveci. A su vez, en presencia de SDRA los falsos negativos radiológicos tienden a incrementarse $\mathrm{e}^{19}$.

Proposiciones alternativas para los criterios de Johanson han sido planteadas por Pugin y cols, y conocidas como CPIS (Clinical Pulmonary Infection Score) (Tabla $2)^{21}$. Las variables que incluye corresponden a temperatura, recuento de leucocitos, volumen y características de las secreciones traqueo-bronquiales, oxigenación, infiltrados pulmonares y cultivos semi-cuantitativos de secreciones traqueo-bronquiales. En esta escala, un pun- taje mayor a 6 se correlaciona positivamente con NAVM. La sensibilidad observada ha sido cercana a $70 \%$ pero con una especificidad variable (42 a $85 \%)^{13,22}$. Como puede apreciarse, esta escala no resuelve las limitaciones de los criterios de Johanson, incluye algunos aspectos difíciles de aplicar en la práctica clínica referidas al volumen y tipo de secreciones bronquiales y además se apoya en criterios microbiológicos semi-cuantitavos que tampoco están disponibles en la evaluación inicial.

Una revisión sistemática publicada el año 2007 y que sólo incluyó trabajos con neumonía confirmada por métodos histológicos, evaluó diferentes tests y combinaciones de pruebas a través de la razón de probabilidad (likelihood ratio; LR). Este parámetro usa los valores de sensibilidad y especificidad para establecer cómo la probabilidad pretest se modifica con la aplicación del test respectivo para indicar la probabilidad, en este caso, de NAVM. Un valor LR positivo indica que el test o combinación de pruebas

\section{Tabla 2. Algunas estrategias diagnósticas utilizadas en el diagnóstico de neumonía asociada a ventilación mecánica}

$\begin{array}{ll}\text { Tipo de técnica } & \text { Ejemplos } \\ \text { Invasoras } & \text { Fibrobroncoscopia con cepillo } \\ & \text { protegido } \\ & \text { Fibrobroncoscopia con lavado } \\ & \text { broncoalveolar } \\ & \text { Biopsia pulmonar y cultivo de tejido a } \\ & \text { cielo abierto } \\ & \text { Cultivo simple de aspirado } \\ & \text { endotraqueal (cualitativo) } \\ & \text { Cultivo cuantitativo de aspirado } \\ & \text { endotraqueal } \\ & \text { Cultivo mediante catéter telescopado } \\ & \text { protegido a ciegas } \\ & \text { Cepillo protegido a ciegas } \\ & \\ & \text { Lavado broncoalveolar a ciegas } \\ \text { CPIS (Clinical pulmonary infection } \\ \text { score) }\end{array}$

Otras técnicas Hemocultivos

Recuento de microorganismos intracelulares

Estudio de Legionella sp

Detección por cultivo, RPC o inmunofluorescencia de agentes virales de neumonía

Bio-marcadores

\section{Comentarios}

Requiere instrumental sofisticado y personal médico altamente capacitado. Estrategia costosa (procedimiento, equipo e insumos) y operativamente restringida. Riesgo de complicaciones. Contraindicaciones formales

Consideraciones similares al caso anterior

Requiere intervención quirúrgica y manejo postoperatorio. Riesgo de complicaciones importantes. Alternativa muy restringida

Técnica sensible, fácil de realizar, operativamente disponible las 24 horas del día. Aplicable universalmente. Su mayor limitación es el exceso de falsos positivos (baja especificidad) lo que lleva a tratamientos innecesarios Ventajas similares al caso anterior. Sin embargo, tiene mejor especificidad

Con similares ventajas que el cultivo cualitativo o cuantitativo endotraqueal. Restricciones asociadas al costo de los insumos

Con similares ventajas que el cultivo cualitativo o cuantitativo endotraqueal. Restricciones asociadas al costo de los insumos

Con similares ventajas que el cultivo cualitativo o cuantitativo endotraqueal. Riesgo de desaturación descrito Asigna puntaje a diferentes parámetros (temperatura, recuento leucocitos en sangre, $\mathrm{PaFiO}_{2}$, radiografía de tórax, cantidad y tipo de secreciones traqueales y resultados semicuantitativos del cultivo de aspirado traqueal). Un puntaje $>6$ se asocia a mayor probabilidad de NAVM. La puntuación se calcula al primer y luego al tercer día. La sensibilidad y especificidad no superan otras técnicas y posee criterios que se evalúan subjetivamente

Baja sensibilidad y especificidad. Sin embargo, se considera un examen fundamental por las implicancias en el diagnóstico y en el tratamiento del paciente

Estrategia de rápida obtención. Sólo validado en LBA por FBC. Limitaciones en sensibilidad y especificidad. Niveles de corte variables

Habitualmente como detección de antígeno de Legionella sp en orina o serología pareada. Permite detectar raros casos de neumonías nosocomiales por este agente

Estudio importante de realizar en caso de sospecha de brotes nosocomiales y para la detección de agentes virales emergentes como herpes simplex tipo 1. Tecnología disponible (inmunofluorescencia: IF) en el país en varios centros. Sensibilidad limitada en caso de IF en adultos

Determinaciones de diferentes moléculas específicas en sangre o fluido alveolar. La procalcitonina ha demostrado un mejor rendimiento que la proteína $C$ reactiva para el seguimiento de pacientes

LBA: lavado broncoalveolar. FBC: fibrobroncoscopia. RPC: reacción de polimerasa en cadena. 
aumenta la probabilidad de la enfermedad y un valor negativo, disminuye esta probabilidad ${ }^{23}$. Este enfoque permitió establecer que los criterios clínicos en forma aislada o combinada entre sí (sin apoyo radiológico), tienen una pobre utilidad diagnóstica evaluada ( $\mathrm{LR}$ 1,2 $\mathrm{IC}_{95}$ 0,76-1,9). En contraste, los criterios que tuvieron un valor LR positivo significativo correspondieron a la aparición de nuevos infiltrados en la radiografía, a una alta celularidad en el lavado broncoalveolar (LBA) (> 400.000 células totales $/ \mathrm{mL}$ ), a la existencia de $>50 \%$ de PMN en el LBA, o a un recuento $>10^{6} \mathrm{ufc} / \mathrm{mL}$ en el cultivo cuantitativo del aspirado endotraqueal ${ }^{23}$. La combinación de criterios radiológicos, en conjunto con dos o más criterios clínicos (fiebre, leucocitosis o secreciones purulentas), alcanzó el límite de la significación estadística. (LR positivo de 2,8; $\mathrm{IC}_{95}$ 0,97-7,9). El uso del CPIS también alcanzó un valor marginal (LR positivo de 2,1; $\mathrm{IC}_{95} 0,92$ a 4,8).

El estudio citado también entrega información sobre aquellos exámenes que indican una baja probabilidad de NAVM. Entre ellos se incluyen un recuento $<400.000$ células totales $/ \mathrm{mL}$ en el LBA (LR negativo 0,$11 ; \mathrm{IC}_{95}$ $0,0-0,40$ ), ausencia de nuevos infiltrados (LR negativo de 0,$\left.35 ; \mathrm{IC}_{95} 0,14-0,87\right)$, ausencia de broncograma aéreo único o múltiples ( $\mathrm{LR}$ negativo 0,29; $\mathrm{IC}_{95} 0,11-0,73$ ), infiltrados radiológicos en ausencia de fiebre, leucocitosis o secreciones purulentas (al menos dos ausentes) (LR negativo 0,$41 ; \mathrm{IC}_{95} 0,17-0,99$ ) o un CPIS $<6$ puntos (LR negativo 0,$\left.38 ; \operatorname{IC}_{95} 0,20-0,74\right)^{23}$.

\section{La necesidad de un diagnóstico apropiado}

El diagnóstico de la NAVM debe ser realizado con un bajo margen de error para mejorar el pronóstico de aquellos que tienen NAVM y además, evitar la exposición innecesaria de los pacientes a tratamientos antimicrobia$\operatorname{nos}^{7-10}$. El diagnóstico adecuado es necesario también, para disminuir la presión selectiva sobre diferentes especies bacterianas y evitar la aparición de aislados multiresistentes de Pseudomonas aeruginosa, Staphylococcus aureus, Enterococcus spp. y otras especies, los que han sido asociados en algunos casos a un incremento en la mortalidad de la NAVM ${ }^{7,24,25}$. Finalmente, el diagnóstico se hace necesario para dirigir oportunamente el estudio y tratamiento hacia causas infecciosas no consideradas o hacia diagnósticos alternativos.

\section{Estrategias diagnósticas en NAVM}

Numerosas técnicas han sido utilizadas para apoyar el diagnóstico de NAVM. La diversidad existente se explica por las limitaciones en sensibilidad y especificidad que tienen cada una de ellas y por la búsqueda de opciones no invasoras sobre aquellas invasoras. Se debe recalcar que estas estrategias cobran sentido cuando se aplican a pacientes con sospecha de NAVM y que esta sospecha, a su vez, debe estar respaldada por información clínica y radiológica combinada ${ }^{23}$. En la Tabla 2 se entrega una clasificación (arbitraria) de aquellas técnicas más evaluadas en la literatura científica. A continuación se detallan algunas características de estas técnicas.

\section{Técnicas invasoras}

Cepillo protegido (CP) mediante fibrobroncoscopia. Esta técnica tiene por objetivo tomar una muestra del árbol respiratorio inferior evitando la contaminación oro-faríngea. El extremo protegido del cepillo es capaz de retirar $0,001 \mathrm{ml}$ de secreción presente en la vía respiratoria. Valores $\geq 10^{3} \mathrm{ufc} / \mathrm{ml}$ se consideran positivos para el diagnóstico de NAVM ${ }^{5}$.

Diferentes estudios han evaluado específicamente el rendimiento del $\mathrm{CP}$ en la NAVM, observándose una sensibilidad que fluctúa entre 60 y $100 \%{ }^{22,26-43}$. La especificidad observada bordea el $70 \%$ cuando este parámetro ha sido evaluado en pacientes conectados a VM pero sin NAVM (Tabla 3$)^{44.45}$. Las limitaciones en la sensibilidad de la técnica son explicadas, entre otros

Tabla 3. Valores descritos de sensibilidad y especificidad para LBA, CP, cultivo cuantitativo de AET, criterios de Johanson y cols, y otros métodos diagnósticos

\begin{tabular}{|c|c|c|c|}
\hline Técnica & $\begin{array}{c}\text { Sensibilidad } \\
(\%)\end{array}$ & $\begin{array}{l}\text { Especificidad } \\
(\%)\end{array}$ & $\begin{array}{c}\text { Punto de corte } \\
\text { uf } / \mathrm{ml}\end{array}$ \\
\hline CP-FBC & $60-100$ & 70 & $10^{3}$ \\
\hline LBA-FBC & $22-100$ & 88 & $10^{4}$ \\
\hline Cuantitativo de AET & $\begin{array}{l}69-70 \\
71-82\end{array}$ & $\begin{array}{l}70-92 \\
83-89\end{array}$ & $\begin{array}{l}10^{5} \\
10^{6}\end{array}$ \\
\hline Cultivo simple de AET & $60-90$ & $0-30$ & No aplicable \\
\hline LBA a ciegas o mini-LBA & 74 & 70 & $10^{4}$ \\
\hline Catéter telescopado protegido (CTP) & 78 & 100 & $10^{3}$ \\
\hline Radiografía de tórax & $57-92$ & $33-70$ & No aplicable \\
\hline Leucocitosis & $77-100$ & $20-58$ & $>10-12 \times 10^{9} / \mathrm{mL}$ \\
\hline Secreciones purulentas & 69 & 42 & No aplicable \\
\hline Fiebre & $42-100$ & $20-46$ & $>38,3^{\circ} \mathrm{C}$ \\
\hline $\begin{array}{l}\text { Criterios clínicos y radiológicos de } \\
\text { Johanson y cols }\end{array}$ & 69 & 75 & No aplicable \\
\hline $\begin{array}{l}\text { Recuento de microorganismos } \\
\text { intracelulares }\end{array}$ & $37-100 \%$ & $89-100 \%$ & $\begin{array}{l}\text { Criterios variables } \\
\text { desde } 1 \text { a } 15 \%\end{array}$ \\
\hline Clinical Pulmonary Infection Score & $72-77$ & $42-85$ & $>6$ \\
\hline \multicolumn{4}{|c|}{$\begin{array}{l}\text { LBA: lavado brocoalveolar. CP: cepillo protegido. AET: aspirado endotraqueal. FBC: fibrobroncosco- } \\
\text { pia. Los datos contenidos en la tabla han sido tomados de referencias citadas en el texto (ref } 15,21 \text {, } \\
27-29,43-45,48-54) \text {. }\end{array}$} \\
\hline
\end{tabular}


factores, por la naturaleza multifocal de la NAVM que limita la obtención de una muestra adecuada ${ }^{28}$, por el uso previo de antimicrobianos, especialmente si ha sido iniciado o modificado en las últimas 72 horas y por la pesquisa de casos en etapas precoces ${ }^{46,47}$. Por otra parte, las limitaciones en la especificidad de esta técnica $(\sim 30 \%$ de falsos positivos) se derivan de la contaminación de la muestra durante su paso por las vías superiores o por el tubo endotraqueal ${ }^{5}$. En algunos pacientes con enfermedad pulmonar obstructiva crónica-EPOC o bronquiectasias, pueden existir recuentos significativos sin infección parenquimatosa asociada (falsos positivos) debido a una carga bacteriana bronquial elevada ${ }^{5}$.

Lavado broncoalveolar (LBA) por fibrobroncoscopia. Este un método que permite obtener un lavado del compartimiento alveolar que se encuentra distal al fibrobroncoscopio impactado en un bronquio subsegmentario. No hay acuerdo en el volumen de solución salina $(\mathrm{NaCl}$ 9/ ${ }_{00}$ estéril) que se debe instilar, el que fluctúa entre 100 y $240 \mathrm{ml}^{5}$. La sensibilidad varía entre 22 y $100 \%$, con un valor promedio de $69 \%$, la cual depende de los mismos factores comentados para $\mathrm{CP}$ (Tabla 3$)^{55,56}$. La especificidad promedio es de $88 \%{ }^{5}$. Se ha sugerido que un LBA con un recuento menor de $50 \%$ de neutrófilos hace improbable la $\mathrm{NAVM}^{23}$. El nivel de corte considerado positivo para el LBA es de $10^{4} \mathrm{ufc} / \mathrm{ml}^{5}$.

Biopsia pulmonar. Los estudios histopatológicos del pulmón han sido considerados como el patrón de referencia en la mayoría de los estudios que han evaluado el rendimiento de diversas técnicas diagnósticas para NAVM. ${ }^{5}$ No obstante, esta técnica ha sido cuestionada en cuanto a su reproducibilidad debido a la discordancia entre los informes histopatológicos del mismo operador o entre diferentes operadores ${ }^{57}$. Por sus dificultades operativas, esta técnica no tiene cabida en el algoritmo diagnóstico de la NAVM en paciente inmunocompetentes, salvo cuando se haga con fines de investigación.

\section{Técnicas no invasoras}

Técnicas no invasoras a ciegas. Tanto el CP como el LBA se han aplicado en forma no invasora (a ciegas) para el estudio de NAVM. En el caso del CP, se ha usado sólo o con un catéter que se avanza por el tubo endotraqueal hasta impactar en un bronquio para luego, a través de él introducir el $\mathrm{CP}^{58}$. El rendimiento publicado con estas técnicas es similar al demostrado por vía broncoscópica; es posible, sin embargo, que para NAVM en zonas de difícil acceso este resultado sea diferente (por ej: NAVM en lóbulos superiores) $)^{5}$.

En el caso del LBA a ciegas, se han usado minilavados $(40 \mathrm{ml})$ y también han demostrado un rendimiento similar al LBA clásico por vía fibrobroncoscópica ${ }^{5,10,48,59}$. El punto de corte recomendado es de $10^{3}$ ó $10^{4} \mathrm{ufc} / \mathrm{ml}$ (Tabla 3$)^{25,60}$.

También se ha aplicado el cultivo cuantitativo mediante un catéter telescopado protegido (CTP) dirigido a ciegas. El catéter interno se avanza al encontrar un tope y se aspiran secreciones con una jeringa vacía ${ }^{54}$. El punto de corte para el reconocimiento de NAVM es $10^{3} \mathrm{ufc} / \mathrm{mL}$ y fue establecido en estudios postmortem con un escaso número de pacientes (Tabla 3 ). Esta técnica no ha sido utilizada en estudios prospectivos sobre mortalidad en NAVM.

Cultivo cuantitativo de aspirado endotraqueal. Diferentes estudios han demostrado que el cultivo cuantitativo de aspirado endotraqueal (AET) tiene un razonable rendimiento diagnóstico en la NAVM. Su sensibilidad y especificidad son cercanas a $70 \%$ usando puntos de corte de $10^{5}$ ó $10^{6} \mathrm{ufc} / \mathrm{ml}$ (Tabla 3$)^{15}$. Varios estudios han demostrado una similitud con técnicas fibrobroncoscópicas. Tiene la gran ventaja que puede ser tomado en cualquier momento y sin necesidad de equipo y personal especializado. El nivel de corte utilizado en la mayor parte de los estudios corresponde a $10^{5} \mathrm{ufc} / \mathrm{ml}^{15,29,30,40,45,49,60}$. La metodología respectiva se presenta en un documento anexo.

Cultivo simple de aspirado endotraqueal. Es quizás la técnica más recurrida, aunque de muy baja especificidad, con valores que fluctúan entre 0 y $30 \%$. Su sensibilidad

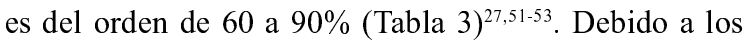
valores relativamente altos de sensibilidad, resultados negativos con esta técnica podrían ser utilizados para descartar la posibilidad de NAVM, siempre y cuando no se hayan efectuado modificaciones en el tratamiento antimicrobiano en las últimas 72 horas. Sin embargo, la mayor parte de las veces el cultivo demuestra crecimiento bacteriano, lo que impide utilizar este criterio para excluir un caso de NAVM. La baja especificidad del cultivo simple favorece el uso irracional de antimicrobianos. Sin embargo, y como se comentará más adelante, esta estrategia no ha afectado negativamente el pronóstico del paciente y puede ser considerada ante la imposibilidad de contar con cultivos cuantitativos.

Clinical Pulmonary Infection Score. Este sistema de puntuación integra información clínica, radiológica, fisiopatológica y microbiológica (Tablas 2 y 3 ). Algunos de sus componentes son subjetivos (cantidad de secreciones), o semi-cuantitativos (cultivo de secreciones traqueales). El puntaje se debe recalcular al tercer día para incorporar la información microbiológica. Su sensibilidad en estudios de mejor diseño fluctúa entre 72 y $77 \%$ con una especificidad de 42 a $85 \%$. Como se comentó antes, en una revisión sistemática, su rendimiento diagnóstico aparece sólo marginalmente úti1 ${ }^{13,21,23}$. 


\section{Otras técnicas}

Hemocultivos. Se ha sugerido que las bacteriemias complican $\sim$ el $8 \%$ de las $\mathrm{NAVM}^{61}$. No obstante, su real significado es incierto ya que, en pacientes críticos, menos de la mitad de los casos de bacteriemia tienen un origen pulmonar $^{26}$.

Recuento de microorganismos intracelulares. La determinación del porcentaje de bacterias intracelulares fue derivada del LBA, como una forma de aumentar el rendimiento de éste. La lectura se realiza sobre 200 leucocitos en el campo de mayor aumento luego de aplicar una tinción de Gram o May-Grünwald-Giemsa. El porcentaje considerado positivo varía en las diferentes publicaciones con valores entre 1 y $25 \%$. La sensibilidad de esta aproximación oscila entre 37 y $100 \%$ y su especificidad entre 89 y $100 \%{ }^{21,33,55,56,62-65}$. Esta técnica sólo ha sido validada para LBA.

\section{Patrón de referencia o estándar de oro no disponible}

Los valores de sensibilidad y especificidad de las metodologías cuantitativas para el diagnóstico de NAVM han sido obtenidos a pesar de que se reconoce la falta de un patrón de referencia o estándar de oro apropiado para esta condición. Se ha propuesto utilizar como criterios de referencia (verdaderos positivos) aquellos casos de NAVM documentados por hemocultivos, cultivo de líquido pleural, de tejidos, o mediante estudio histológico. Sin embargo, la utilización de hemocultivos está limitada por su baja positividad y la posibilidad de que la bacteriemia no tenga un origen pulmonar. De la misma manera, el estudio histológico presenta limitaciones en la reproducibilidad como se ha comentado anteriormente y los casos definidos por cultivos pleurales tienen el inconveniente de la baja frecuencia de esta complicación y de la naturaleza multifocal de la NAVM. A pesar de los sesgos reconocidos, estos criterios constituyen la mejor definición de casos disponible con las tecnologías actuales. Por ello, la simple utilización de puntos de corte no constituye un patrón de referencia absoluto para el reconocimiento de NAVM. La ausencia de un estándar de oro ha sido reconocida en la literatura médica ${ }^{49,66}$.

\section{Impacto sobre el pronóstico del paciente utilizando diferentes estrategias diagnósticas}

Los métodos diagnósticos microbiológicos en NAVM pueden ser aplicados para respaldar o cuestionar el uso de un esquema antimicrobiano mediante la confirmación o exclusión de una sospecha diagnóstica, reunir información epidemiológica local sobre la resistencia prevalente en una unidad de hospitalización o sobre sus cambios en el tiempo, redirigir el estudio hacia causas alternativas en casos no confirmados y ajustar la terapia mediante una reducción, ampliación o cambio de la cobertura antimicrobiana.

Una cobertura microbiológica apropiada en el esquema inicial de tratamiento es fundamental en el pronóstico de la NAVM. Diferentes autores han demostrado que la mortalidad atribuible de esta condición está estrechamente ligada a este factor ${ }^{8-10,67-69}$, especialmente en los casos de NAVM de presentación tardía, debido a su asociación con microorganismos multi-resistentes ${ }^{25}$. Las modificaciones terapéuticas posteriores ( $>72$ horas), realizadas con la información microbiológica obtenida en cada caso, no logran modificar su pronóstico ${ }^{8,9}$.

Debido a que no existe actualmente un método diagnóstico ideal para el reconocimiento de la NAVM, la selección de un método sobre otro ha descansado en la evaluación del impacto para disminuir la mortalidad, el consumo de antimicrobianos o la estadía hospitalaria.

Hasta la fecha se han desarrollado cinco estudios randomizados y prospectivos que han comparado métodos invasores versus métodos no invasores para medir estos parámetros, todos ellos publicados en los últimos 10 años (Tabla 4) ${ }^{60,70-73}$. Dos de ellos han utilizado el cultivo cuantitativo de AET y tres el cultivo simple (cualitativo) de AET como método no invasor. El método invasor ha sido el LBA mediante fibrobroncoscopia, en algunos casos con CP. En cuatro de estos estudios se estandarizó el tratamiento antimicrobiano.

La experiencia publicada indica que en cuatro de los cinco estudios no se demostraron diferencias en mortalidad entre los métodos invasores respecto a los métodos no invasores, conclusión que incluye a lo observado en el trabajo más reciente e importante desarrollado, de carácter multicéntrico y que en número de pacientes supera lo acumulado en los otros trabajos ${ }^{73}$.

Sólo un trabajo revela que el uso de un método no invasor (cultivo cualitativo), estuvo asociado a una mayor mortalidad a los 14 días pero no a los 28 días y que el grupo manejado con técnicas diagnósticas invasoras, estuvo asociado a un mayor número de días sin uso de antimicrobianos y a un menor consumo diario de ellos ${ }^{71}$. Sin embargo, los resultados de este trabajo han sido criticados porque la "rama no invasora" tenía un mayor porcentaje de pacientes que recibieron tratamiento antimicrobiano inapropiado (13 vs 1\%) y porque el diseño estuvo sesgado a favor de la suspensión de antimicrobianos en la "rama invasora" cuando el paciente no tenía agentes identificados en la tinción de Gram y no estaba en una condición muy grave ${ }^{74}$. Sólo $52 \%$ de los pacientes en la "rama invasora" recibió antimicrobianos empíricos versus 91\% en la "rama no invasora" 71.

Un meta-análisis publicado el año 2005 que incluye cuatro de los cinco trabajos publicados hasta entonces, 
Tabla 4. Estudios disponibles sobre impacto en la evolución de pacientes con neumonía asociada a ventilación mecánica según técnicas diagnósticas

\section{Autor y año (ref)}

Sánchez-Nieto et al, 1998 (ref 70)

Fagon et al, 2000

(ref 71)

Diseño

Estudio randomizado, abierto y prospectivo

Estudio randomizado, abierto y prospectivo

Solé-Violán et al, 2000

(ref 72)

Ruiz et al, 2000

(ref 60)*

Estudio randomizado, abierto y prospectivo

Estudio randomizado multicéntrico abierto y prospectivo

Estudio randomizado, abierto y prospectivo (ref 73)

\section{Comparación}

CP-FBC, LBA-FBC versus cultivo cuantitativo de AET

24 pacientes en cada rama

CP-FBC O LBA-FBC versus cultivo simple de AET.

204 y 209 pacientes en cada rama

CP-FBC y $L B A-F B C$ versus cultivo simple de AET

45 y 43 pacientes en cada rama

CP-FBC, LBA-FBC versus cultivo cuantitativo de AET

37 y 39 pacientes en cada rama

LBA-FBC versus cultivo simple de AET 365 y 374 pacientes en cada rama

\section{Principales hallazgos}

Sin diferencias en las tasas de mortalidad cruda o ajustada entre ambas ramas. Sin diferencias en la estadía en UTI o en duración de VM

Diferencias en mortalidad con redución de eventos fatales precoces en la "rama invasora". Menor uso de antimicrobianos

Sin diferencias en las tasa de mortalidad, en días de hospitalización en UTI o en duración de la VM

Sin diferencias en las tasa de mortalidad, en días de hospitalización en UTI o en duración de la VM

\section{Comentarios}

Primer trabajo publicado al respecto, sin estandarización de tratamiento antimicrobiano

Con estandarización de tratamiento antimicrobiano

Con estandarización de tratamiento antimicrobiano

Con estandarización de tratamiento antimicrobiano. Describe ahorro en costos operativos con métodos no invasores

Sin diferencias en las tasa de mortalidad a 28 días, en uso de antimicrobianos o en días de hospitalización

Con estandarización de tratamiento antimicrobiano en UTI

*Publicaciones consecutivas e independientes del mismo grupo de investigación. CP: cepillo protegido. LBA: lavado broncoalveolar. FBC: fibrobroncoscopia. AET: aspirado endotraqueal. VM: ventilación mecánica.

no encontró diferencias en mortalidad ${ }^{75}$ y en un análisis incluido en el último trabajo desarrollado, la combinación de los resultados de estos cinco trabajos no demostró diferencias en mortalidad entre diferentes estrategias invasoras (RR 0,93 IC95 0,76-1,15) 73 .

Dos de estos cinco trabajos han evaluado el pronóstico asociado al uso de técnicas cuantitativas-invasoras en comparación con los resultados obtenidos por métodos cuantitativos no invasores ${ }^{60,70}$. En uno de estos estudios, Ruiz y cols, demostraron que no hubo diferencias en mortalidad, ya fuese que los pacientes se estudiaran mediante cultivos cuantitativos de AET (técnica no invasora), o mediante cultivos cuantitativos de CP o LBA obtenidos por fibrobroncoscopia ${ }^{60}$. Tanto la estadía hospitalaria como la duración de la VM, la tasa de mortalidad global y la letalidad fueron similares en ambos grupos. Estas similitudes contrastaron con el bajo costo asociado al cultivo cuantitativo de AET, que fue menos de $10 \%$ del costo asociado a los cultivos por técnicas invasoras; este es el único estudio que ha efectuado una evaluación económica de este enfoque.

Se debe mencionar que el rendimiento de las técnicas diagnósticas cuantitativas no parece ser modificado por el uso previo de antimicrobianos, siempre y cuando ellos no hayan sido alterados o iniciados en la 48 ó 72 horas previas al estudio cuantitativo ${ }^{46}$.
Debido a que los métodos no invasores no afectan la mortalidad y cuando se corrigen los sesgos tampoco el uso de antimicrobianos, la conclusión más importante es que la selección de la fibrobroncoscopia para el diagnóstico de NAVM no ofrece ventajas en el pronóstico del paciente. Además, es una estrategia más onerosa, requiere recursos humanos no siempre disponibles y tiene sus riesgos. Por ello, el consenso publicado el año 2001 recomendó adoptar una estrategia diagnóstica no invasora para el reconocimiento de la NAVM. El último trabajo disponible sobre este tema, publicado después del consenso anterior, respalda esta estrategia y permite recomendar nuevamente la utilización de una estrategia diagnóstica no invasora para reconocer cuadros de NAVM. 1A.

Algunos valores descritos en la literatura médica sobre la sensibilidad, especificidad y puntos de corte de recuentos cuantitativos en LBA, CP y cultivo cuantitativo de AET, junto a otras estrategias diagnósticas, se señalan en la Tabla 3 . Los puntos de corte actualmente aceptados se basan en factores que tienden a maximizar las características de rendimiento de las pruebas más que a factores relacionados con su utilidad desde una perspectiva terapéutica.

Debe destacarse que el diagnóstico con métodos microbiológicos invasores o no invasores no es superior a los criterios de sospecha clínica para el reconocimiento 
de NAVM ya que ofrece sensibilidades y especificidades similares (Tabla 3). Sin embargo, son recomendados porque, a diferencia de los criterios de Johanson, permiten recolectar información etiológica, la que es fundamental para el tratamiento con esquemas antimicrobianos apropiados en los futuros pacientes. A pesar de que no fue un planteamiento explicitado previamente, este consenso, incorpora la recomendación de utilizar alguna estrategia diagnóstica que entregue información microbiológica. 1A.

Hasta la fecha no se han comparado directamente, métodos no invasores cuantitativos y cualitativos entre sí para ver su impacto en mortalidad.

El hallazgo de recuentos microbianos no significativos ha sido utilizado por algunos grupos para justificar la suspensión del tratamiento antimicrobiano. Esta aproximación se fundamenta en la baja probabilidad del diagnóstico en presencia de recuentos bajo un punto de corte definido, reportes de que esta estrategia no está asociada a un incremento de la tasa de recurrencia o mortalidad en comparación con el grupo de pacientes tratados con antimicrobianos, las ventajas de evitar el uso innecesario de fármacos en pacientes graves, la baja presión selectiva derivada de esta conducta y el potencial beneficio económico de este enfoque ${ }^{76,77}$. Sin embargo, otros grupos no suspenden el tratamiento iniciado empíricamente a pesar de un recuento bajo, aduciendo que estos criterios excluyen de los beneficios de la terapia a un porcentaje no despreciable de pacientes (hasta $25 \%$ ) debido a la baja sensibilidad de estas metodologías y a que la evidencia sobre la falta de impacto de la suspensión de antimicrobianos está basada en ensayos de diseño no concluyente ${ }^{60}$. En el ámbito clínico, el diagnóstico microbiológico cuantitativo de la NAVM ha sido útil para mejorar la seguridad del médico tratante en el diagnóstico de la neumonía y para ayudar a modificar el esquema terapéutico inicial ${ }^{77}$.

\section{Bio-marcadores}

Se entiende bajo este concepto al uso de moléculas humanas en el diagnóstico o pronóstico de diferentes condiciones infecciosas, incluyendo NAVM. Cinco de ellas han tenido una investigación más extensa y se incluyen en esta revisión. Los bio-marcadores son determinados en diferentes fluidos y algunos de ellos sólo son utilizados en la toma de decisiones inicial, sin una utilización posterior en el paciente. Las moléculas corresponden a: copeptina, receptor soluble gatillante de células mieloides, citoquinas, procalcitonina $(\mathrm{PCT})$ y proteína $\mathrm{C}$ reactiva $(\mathrm{PCR})$.

Copeptina. La vasopresina arginina (VPA) se libera en el organismo en respuesta a estímulos tales como la hipotensión arterial, hipoxia, hiperosmolaridad, acidosis e infecciones. Esta hormona tiene propiedades vasocons- trictoras, antidiuréticas y mejora la respuesta vasopresora en casos de vasodilatación. Se deriva de una molécula precursora conocida como preproVPA junto a otros dos péptidos: neurofisina II y la copeptina. La copeptina es un péptido estable que permite sus mediciones y que se eleva en casos de sepsis y shock séptico en forma paralela al aumento de VPA. Se han descrito experiencias señalando el valor pronóstico de copeptina en pacientes con sepsis (valores más altos en los no sobrevivientes), bronquitis crónica reagudizada que requieren hospitalización o en pacientes ingresados por neumonía ${ }^{78}$. Esta molécula también ha sido estudiada en pacientes con NAVM. Los valores en personas sanas bordean los $4 \mathrm{pmol} / \mathrm{L}$. Se determina en una muestra de suero o plasma ${ }^{78}$.

En un estudio que incluyó 71 pacientes con NAVM publicado el año 2008, se identificó mediante curvas receptor-operador (ROC) un valor umbral de $64,8 \mathrm{pmol} / \mathrm{L}$ el día de la sospecha diagnóstica para predecir mortalidad, con una sensibilidad y especificidad de $69 \%$ para este desenlace. El mismo estudio identificó un valor de 43 $\mathrm{pmol} / \mathrm{L}$ al cuarto día de evolución con una sensibilidad superior $(80 \%)$ pero menor especificidad $(60 \%)$ para predecir mortalidad ${ }^{78}$. Expresado de otra forma, estos resultados indican que los no sobrevivientes tienen valores más altos de este bio-marcador que los sobrevivientes. El análisis multivariado confirmó la asociación independiente de valores elevados de copeptina con un mayor riesgo de muerte, un fenómeno no observado con el puntaje APACHE II en el mismo estudio.

La medición de este péptido tiene ventajas asociadas, entre las que destaca su estabilidad para efectuar mediciones rápidas independientes de un operador y su asociación con un peor pronóstico. No obstante, presenta varias limitaciones, entre las que se incluyen la naturaleza preliminar de estos ensayos, su utilidad predictora en mortalidad pero no para reconocer enfermedad o diagnósticos diferenciales. Por ejemplo, sus valores también están elevados en pacientes con falla cardíaca ${ }^{79}$. Por ahora, no puede considerarse como un elemento de apoyo clínico cotidiano en pacientes con sospecha de NAVM y este grupo no recomienda su uso (Tabla 5). 2D.

Receptor soluble gatillante en células mieloides. Esta molécula, conocida también como TREM-1 (triggering receptor expressed on myeloid-1 cells), integra la superfamilia de las inmunoglobulinas y se expresa en neutrófilos y en algunos monocitos. Participa en la respuesta inflamatoria frente a productos microbianos mediante el reconocimiento de patrones moleculares y gatilla la producción de citoquinas inflamatorias. En tejidos infectados, los neutrófilos y monocitos expresan altos niveles de TREM-1, no ocurriendo así en situaciones con inflamación pero sin infección ${ }^{80}$. Este receptor está unido a la membrana celular pero se puede detectar una 
Tabla 5. Bio-marcadores utilizados en el manejo de la sepsis o neumonía asociada a ventilación mecánica

$\begin{array}{ll}\text { Marcador } & \text { Origen del marcador } \\ \text { Copeptina } & \begin{array}{l}\text { Liberado por neurohipófisis en respuesta a hipotensión } \\ \text { arterial, acidosis, infecciones, hipoxia }\end{array} \\ \begin{array}{l}\text { Receptor soluble gatillante } \\ \text { de células mieloides }\end{array} & \begin{array}{l}\text { En tejidos infectados, los neutrófilos y monocitos expresan } \\ \text { altos niveles de TREM-1, no ocurriendo así en situaciones } \\ \text { con inflamación pero sin infección }\end{array} \\ \text { Citoquinas } & \text { Mediadores de inflamación } \\ \text { Procalcitonina (PCT) como } & \begin{array}{l}\text { Propéptido de la calcitonina } \\ \text { determinación aislada inicial }\end{array} \\ \text { Sus concentraciones aumentan en el plasma frente a un } \\ \text { estímulo infeccioso luego de que su síntesis se incrementa } \\ \text { en células extratiroideas } \\ \text { Aumenta en infecciones asociadas a una respuesta infla- } \\ \text { matoria sistémica o hipoperfusión de un órgano y por ello } \\ \text { se ha planteado su utilidad en escenarios con pacientes } \\ \text { críticos }\end{array}$

PCT como determinación seriada

Proteína $C$ reactiva $(P C R)$
Molécula integrante de la respuesta inmune innata con actividad pro y anti-inflamatoria

\section{Comentarios}

Experiencia preliminar, utilidad predictora en mortalidad pero no para reconoce enfermedad $u$ otros diagnósticos diferenciales. 2D

Resultados contradictorios obtenidos en diferentes ensayos y bajas sensibilidades y especificidades obtenidas con las técnicas posibles de considerar a nivel asistencial (ELISA) para reconocer NAVM

No existen por ahora estudios que hayan evaluado su utilidad para la interrupción de antimicrobianos. 2D

Sin diferencias significativas entre el grupo con o sin infección. Baja sensibilidad y especificidad. 2D

La utilidad de la medición de PCT en pacientes críticos tiene un rendimiento insuficiente para el reconocimiento de pacientes sépticos en un entorno crítico En una revisión de 18 estudios de diseño adecuado se determina una sensibilidad y especificidad global de $71 \%$ para el diagnóstico de sepsis, una cifra de valor limitada

Escasos estudios realizados en pacientes con o sin sepsis demuestran bajo rendimiento en los estudios más importantes (OR $\mathrm{Dg}<25$, lo que señala pobre utilidad). 2E

Su aplicación seriada (cada 5 días) ha permitido reducir significativamente la duración del tratamiento antimicrobianos en pacientes sépticos en $\mathrm{UCI}$. 2B

Un meta-análisis indica que la medición de PCR tiene un rendimiento inferior al uso de PCT para discriminar sepsis de otras condiciones inflamatorias en pacientes críticos. 2E fracción soluble (sTREM-1), explorada como un biomarcador pronóstico o diagnóstico.

Las mediciones de sTREM-1 en el diagnóstico diferencial de pacientes con o sin NAVM se han efectuado en las muestras de LBA o mini LBA a ciegas e inicialmente demostraron resultados favorables que luego han sido más limitados.

En una primera experiencia, desarrollada con la técnica de Westernblot, valores $\geq$ a $5 \mathrm{pg} / \mathrm{mL}$ se asociaron con una alta sensibilidad $(98 \%)$ y especificidad $(90 \%)$ para reconocer casos de $\mathrm{NAVM}^{81}$. La serie inicial fue pequeña e incluyó 46 casos. Los valores elevados dependen del contexto bajo análisis ya que también se presentó el mismo perfil en pacientes con neumonía adquirida en la comunidad que requirieron ventilación y las cifras no se diferenciaron entre ambas condiciones. Posteriormente, en una segunda experiencia, esta vez desarrollada con una técnica de inmunoensayo doble sandwich, los resultados fueron mucho más modestos con una sensibilidad de $75 \%$ y una especificidad de $85 \%$ usando valores $>200 \mathrm{pg} / \mathrm{mL}^{82}$. Es de interés notar que en este último estudio se pudo observar un incremento progresivo de sTREM-1 en el mini-LBA a ciegas en los días previos al reconocimiento de la NAVM y que este aumento también pudo ser utilizado para el diagnóstico, mejorando algo la sensibilidad pero sin igualar los logros del primer estudio y aumentando los gastos y manipulación de la vía aérea. Finalmente, una pu- blicación del año 2007 no permitió demostrar diferencias en los valores de esta molécula en el LBA de pacientes con o sin neumonía asociada a VM, aunque sí en el líquido condensado de la trampa de agua de la rama espiratoria del circuito del VM en aquellos afectados por neumonía ${ }^{83}$.

La medición de valores plasmáticos de sTREM-1 no ha resultado de utilidad para distinguir diferentes condiciones clínicas, como lo demostrara recientemente un estudio en pacientes bajo cuidados intensivos quirúrgicos que no observó diferencias significativas entre los valores plasmáticos de sTREM-1 en pacientes con SRIS, sepsis grave o shock séptico, con muestras analizadas al momento de esta condición, y tampoco entre sobrevivientes o no sobrevivientes con sepsis ${ }^{84}$. Sin embargo, la medición prospectiva de sTREM-1 en el plasma parece ser útil para discriminar aquellos pacientes que responden o no responden a la terapia antimicrobiana, aunque se desconoce si esta práctica reporta una utilidad adicional a la entregada por otros parámetros clínicos o de laboratorio más sencillos ${ }^{85}$.

Los resultados arriba comentados indican que la medición de sTREM-1 para el reconocimiento de NAVM ofrece, por ahora, desventajas que impiden su incorporación como una prueba de apoyo útil en el diagnóstico de esta condición. Estas desventajas incluyen los resultados contradictorios obtenidos en diferentes ensayos y las bajas sensibilidades y especificidades obtenidas con las técnicas 
posibles de considerar en términos asistenciales respecto a otras más engorrosas de mayor rendimiento. No existen, por ahora, estudios que hayan evaluado su utilidad para la interrupción de la antibioterapia. Este grupo tampoco recomienda su incorporación. 2 D.

Citoquinas. La medición del factor de necrosis tumoral alfa (FNT $\alpha)$ y de interleukina $-1 \beta$ en el LBA también se ha analizado en pacientes afectados por NAVM pero sin encontrar diferencias significativas con el grupo sin infección. Por ejemplo, Gibot y cols, comunican valores promedio de 290,5 $\pm 39,7 \mathrm{pg} / \mathrm{mL}$ de FNT $\alpha$ en el LBA de pacientes con NAVM y de 147,2 $\pm 12,5 \mathrm{pg} / \mathrm{mL}$ en casos sin esta condición, con una gran sobreposición que impidió la discriminación. De la misma manera, los valores de interleukina- $1 \beta$ en LBA también presentaron una sobreposición notable $(95,1 \pm 29,4$ y 41,5 $\pm 12,5$ para casos con y sin NAVM, respectivamente) ${ }^{81}$. En la comparación comentada, la evaluación de sTREM-1 tuvo un mejor rendimiento. En otra experiencia, Determann y cols, tampoco logran encontrar un valor diagnóstico en la medición de FNT $\alpha$, interleukina $-1 \beta$ o interleukina- 6 en LBA para el reconocimiento de esta condición. En este trabajo, valores de FNT $\alpha>50 \mathrm{pg} / \mathrm{mL}$ presentaron una sensibilidad de $78 \%$ y una especificidad de $58 \%$; para valores de interleukina $-1 \beta>1.000 \mathrm{pg} / \mathrm{mL}$, la sensibilidad fue de $67 \%$ y la especificidad de $68 \%$ y para interleukina-6, valores $>1.000 \mathrm{pg} / \mathrm{mL}$ presentaron una sensibilidad de $89 \%$ pero con una muy baja especificidad de $58 \% 82$.

Estos antecedentes indican que la utilidad de la medición de estas citoquinas en el LBA no ofrece ventajas en el reconocimiento clínico de esta infección y que no debe recomendarse su uso. 2D.

Procalcitonina. Esta molécula, un propéptido de la calcitonina, se sintetiza normalmente por las células $\mathrm{C}$ del tiroides como una parahormona y como tal, su concentración en el plasma es casi no detectable. Sin embargo, aumentan en el plasma frente a un estímulo infeccioso, luego de que su síntesis se incrementa en células extra-tiroideas. El aumento de sus niveles no obedece a la infección propiamente tal, sino que a condiciones asociadas a una respuesta inflamatoria sistémica o hipoperfusión de un órgano y por ello se ha planteado su utilidad en escenarios con pacientes críticos ${ }^{86,87}$. La PCT puede ser detectada en sangre desde tres horas después de una exposición a endotoxinas bacterianas, alcanzando un valor máximo a las seis horas y permanece en valores estables durante 24 horas $^{87}$. Lamentablemente, varias condiciones no infecciosas se asocian a un aumento en sus niveles plasmáticos, incluyendo la injuria pulmonar por inhalación, aspiración pulmonar, pancreatitis aguda, hipertermia, infarto mesentérico, trauma, quemaduras y cirugía ${ }^{88}$.
La utilidad de la medición de PCT en pacientes críticos tiene un rendimiento insuficiente para el reconocimiento de pacientes sépticos en un entorno crítico, según lo revela una revisión sistemática publicada el año $2007^{89}$. En una revisión de 18 estudios de diseño adecuado, Tang y cols, determinan una sensibilidad y especificidad global de $71 \%$ para el diagnóstico de sepsis, una cifra de valor limitada. La medición de PCT para el reconocimiento de pacientes con NAVM ha sido evaluada en unos pocos estudios. En uno de ellos, Duflo y cols, analizaron el rendimiento de esta molécula en 96 pacientes con sospecha de NAVM en una UCI general de adultos ${ }^{90}$. El diagnóstico de NAVM fue establecido por los criterios clínicos, radiológicos y microbiológicos habituales, en este caso usando un mini-LBA con recuentos $\geq 10^{3} \mathrm{ufc} / \mathrm{mL}$. Aunque los valores de PCT estuvieron significativamente aumentados en el grupo de 44 pacientes con NAVM $(11,5 \mathrm{ng} / \mathrm{mL})$ versus aquel sin esta condición el primer día $(1,5 \mathrm{ng} / \mathrm{mL})$, la sensibilidad obtenida con el mejor punto de corte observado (3,9 ng/ $\mathrm{mL}$ ) fue de sólo $41 \%$, lo que revela que muchos pacientes con NAVM no presentan valores elevados de $\mathrm{PCT}^{90}$. Este aumento persistió en forma significativa hasta el sexto día. En contraste, la especificidad fue óptima (100\%). Por otra parte, y respaldando los hallazgos de otros estudios, las concentraciones de PCT fueron más elevadas en los pacientes que no sobrevivieron respecto a los que así lo hicieron $(16,5 \mathrm{ng} / \mathrm{mL} \text { vs } 2,9 \mathrm{ng} / \mathrm{mL})^{90}$. En este trabajo no se detectaron diferencias significativas en la concentración de PCT alveolar y sus niveles fueron muy discretos.

\section{Potenciales ventajas de la procalcitonina sobre la proteína $C$ reactiva y en el uso acortado de antimicrobianos}

A pesar de las limitaciones comentadas, la PCT tiene dos ventajas detectadas en diferentes estudios: un mejor rendimiento diagnóstico que la medición de PCR y su utilidad para reducir el uso de antimicrobianos cuando se usa en forma seriada.

En un meta-análisis publicado el año 2006, Uzzan y cols, lograron identificar 25 estudios sobre la utilidad diagnóstica de PCT versus PCR para discriminar sepsis de otras condiciones inflamatorias en pacientes adultos críticos quirúrgicos o traumatizados, excluyendo pacientes inmunosuprimidos o de tipo médico ${ }^{91}$. La curva ROC identificó la medición de PCT como un mejor parámetro que la medición de la PCR para el reconocimiento de pacientes críticos con sepsis. El valor $Q^{*}$ que mide la distancia hacia el eje superior izquierdo en una curva ROC (el punto con $100 \%$ de sensibilidad y especificidad), fue de 0,78 para PCT y de 0,71 para PCR, demostrando así, un mejor perfil respecto a la medición de esta última. No obstante, estas cifras no son óptimas y no establecen además, el foco de origen de la sepsis. Estos antecedentes 
indican que la medición de PCT es de mayor utilidad que la determinación de PCR en pacientes críticos.

La PCT ha sido usada también para apoyar la interrupción de antimicrobianos en pacientes críticos. En una experiencia en pacientes adultos en Suiza, Nobre y cols, lograron demostrar que el uso de PCT en un protocolo permitió acortar en promedio $\sim$ cuatro días la exposición a antimicrobianos respecto de un grupo control. El estudio no incluyó pacientes inmunosuprimidos o pacientes con infecciones que requerían tratamientos prolongados por $P$. aeruginosa o Acinetobacter baumannii. Se permitía la interrupción del tratamiento luego de tres días de terapia después de un valor inicial $<1 \mathrm{ng} / \mathrm{mL}$ siempre y cuando el valor de seguimiento descendiera bajo $0,25 \mathrm{ng} / \mathrm{mL}$ y se descartara una infección grave. Para pacientes con cifras iniciales $>1 \mathrm{ng} / \mathrm{mL}$, se permitía la interrupción si el valor se reducía en $90 \%$ o descendía bajo $0,25 \mathrm{ng} / \mathrm{mL}^{92}$.

Estos antecedentes indican que la medición de PCT es una herramienta superior a la medición de la PCR para reconocer pacientes críticos con sepsis grave y con riesgo de morir pero no permite determinar el origen de la infección y, en el caso de NAVM, tampoco descartarla por su baja sensibilidad. Puede ser considerada entonces como una prueba de laboratorio adicional para el estudio de un paciente con SRIS pero no como un examen sustitutivo de los aceptados actualmente. Permite además, reducir la duración de la antibioterapia. 2B.

\section{Traqueo-bronquitis asociada a ventilación mecánica (TAVM)}

Este concepto se ha desarrollado progresivamente en los últimos años y ha despertado interés porque su tratamiento parece ser beneficioso para el paciente. Su frecuencia oscila entre 3 y $10 \%$ de los pacientes intubados en VM y el mecanismo patogénico es similar al observado en NAVM postulándose que representa un estado mórbido de transición que precede a la $\mathrm{NAVM}^{93}$. Esta condición se asocia a una mayor estadía en UCI y duración de la VM.

En términos sencillos, la TAVM corresponde a un

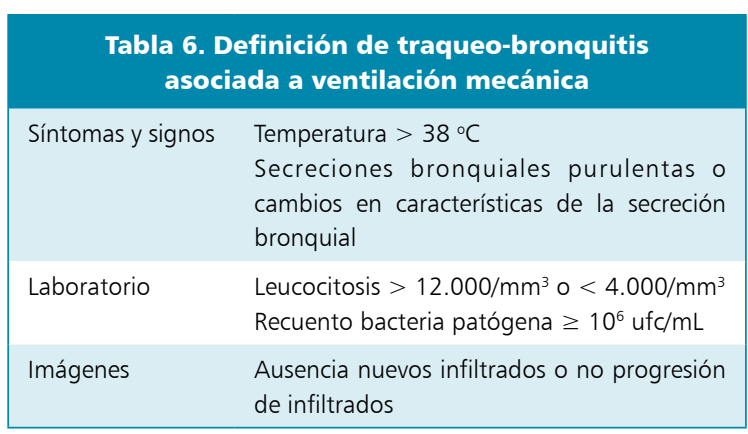

episodio de NAVM sin nuevos infiltrados pulmonares en la radiografía de tórax. La definición más aceptada corresponde entonces a la existencia de fiebre y cambios en la secreción bronquial asociados a cambios de parámetros de laboratorio y un recuento alto de bacterias en el aspirado endotraqueal (Tabla 6).

Debido a que la TAVM representa un estado de transición hacia la NAVM se ha postulado que su tratamiento permitiría disminuir la morbilidad o mortalidad asociada a la NAVM. La información sobre este beneficio proviene hasta ahora de pocos estudios. En un estudio caso-control, los pacientes con TAVM que recibieron antimicrobianos tuvieron una menor estadía en UCI y menos días de VM pero no una menor incidencia de NAVM ${ }^{94}$. Dos estudios randomizados se han desarrollado para evaluar el impacto del tratamiento antimicrobiano en pacientes con TAVM, demostrando ambos diferentes beneficios sobre el paciente y en uno de ellos disminución de la mortalidad (Tabla 7) ${ }^{95,96}$.

A pesar de estas experiencias preliminares, estos antecedentes indican que se ha establecido un nuevo concepto en infecciones asociadas a VM. Este consenso recomienda discriminar la NAVM de la TAVM desde el punto de vista diagnóstico para optimizar el reconocimiento de casos verdaderos de NAVM y potencialmente seleccionar pacientes para el tratamiento de esta nueva condición. B1.

\section{Recomendaciones diagnósticas para pacientes adultos con sospecha de NAVM}

Tomando en consideración los antecedentes señalados, este grupo refuerza las siguientes recomendaciones globales sobre el diagnóstico de la NAVM ya elaboradas el 2001, modifica algunas de ellas y añade otras.

Recomendar el uso de métodos diagnósticos microbiológicos cuando exista sospecha de NAVM. A pesar de que no mejoran el reconocimiento diagnóstico de la NAVM, permiten recopilar información epidemiológica de gran importancia para el tratamiento apropiado de los casos futuros. Ya que la etiología es variable de centro a centro, es fundamental recopilar esta información en forma institucional, ininterrumpida y prospectiva. El planteamiento alternativo de una TQVM también requiere este enfoque. $\mathbf{1 A}$.

Recomendar el uso de técnicas no invasoras sobre las invasoras. Como se comentó, las técnicas no invasoras son más fáciles de implementar, no requieren recursos humanos o equipos sofisticados, están disponibles las 24 horas del día, son de menor riesgo, más económicas y no afectan negativamente la sobrevida del paciente respecto a las estrategias invasoras. 1A. 


\section{Estudio y diseño}

Palmer et al, 2008 (referencia 96)

Randomizado controlado con placebo

Inclusión: $>4 \mathrm{~mL}$ de secreción purulenta en 4 horas con tinción de Gram que demuestra bacterias

Antimicrobianos aerosolizados (vancomicina y/o gentamicina) por 14 días $(n=19)$ vs placebo $(n=24)$. Se permitió uso de antimicrobianos sistémicos

Nseir et al, 2008 (referencia 95)

Randomizado, controlado sin placebo.

Inclusión: Primer episodio de TAVM (recuento $>10^{6} \mathrm{ufc} / \mathrm{mL}$, fiebre

$>38^{\circ} \mathrm{C}$, secreción purulenta por tubo, ausencia de NAVM), no episodios previos de NAVM

Uso de antimicrobianos sistémicos por 8 días $(n=18)$ sin antimicro-

bianos aerosolizados, Grupo control sin placebo $(n=26)$

\section{Beneficios y limitaciones}

Beneficios: Disminución de síntomas propios de NAVM en grupo experimental entre el inicio y los 14 días (73,6 a 35,7\%) pero no en el grupo placebo (75 y 78,6\%), menor tasa de score de infección pulmonar, menor frecuencia de colonización con agentes resistentes, menor leucocitosis a los 14 días, menor frecuencia de cambio de antimicrobianos y mayor tasa de weaning ( 84,2 vs $54,1 \%$ ). Mortalidad similar en ambos grupos

Limitaciones: No se usaron cultivos cuantitativos ni estudio de imágenes para descartar NAVM, algunos pacientes tenían NAVM al inicio en cifras desconocidas, uso concomitante de antimicrobianos sistémicos en forma no randomizada, bajo número de pacientes

Beneficios: Menor tasa de NAVM (11 vs 46\%), días libre de VM (mediana 16 vs 4), menor mortalidad en UCI (0 vs 42\%)

Limitaciones: Bajo número de pacientes, evaluación no ciega de los desenlaces en estudio

Estudio microbiológico con técnicas cuantitativas o técnicas cualitativas. El consenso del año 2001 escogió los procedimientos cuantitativos ya que ellos permitían flexibilizar el trabajo clínico, facilitar la interrupción de antimicrobianos y dirigir en estudio hacia otras causas en caso de recuentos bajos, aspectos no posibles de lograr con los métodos cualitativos. Sin embargo, debido a que los estudios comparativos han demostrado una sobrevida similar con ambos enfoques, algunos expertos cuestionan la necesidad de aplicar métodos cuantitativos, máxime si se considera que agregan mayor costo y complejidad al estudio de laboratorio. En este consenso, se modifica la recomendación previa y se plantea que ambas estrategias pueden ser utilizadas (cultivo simple sin recuento o cultivo cuantitativo). 1A. Sin embargo, se reconoce que la estrategia cuantitativa tiene mayor especificidad y tiene potenciales ventajas secundarias aún no validadas, tales como el disminuir el consumo de antimicrobianos y redirigir oportunamente el estudio hacia otras causas en casos con recuentos bajos. $\mathbf{3 C}$.

Niveles de corte. El uso de dos niveles de corte fue sugerido en el consenso previo $\left(\geq 10^{6} \mathrm{ufc} / \mathrm{mL}\right.$ y $<10^{3}$ $\mathrm{ufc} / \mathrm{mL}$ ). La utilización de diferentes puntos de corte y la reinterpretación de los valores sugeridos en la literatura médica ha sido considerada en algunas publicaciones y análisis teóricos sobre el tema ${ }^{49,97}$. En este sistema, los recuentos altos establecen una mayor probabilidad de NAVM que justifica la mantención de los antimicrobianos o su modificación. En contraste, los recuentos mínimos sugieren una menor probabilidad que obliga a buscar diagnósticos alternativos. Este enfoque permite, en teoría, otorgar flexibilidad a una condición continua, potenciando el beneficio al paciente y disminuyendo los riesgos de la terapia innecesaria. A la fecha, no se ha desarrollado estudio alguno que haya evaluado el impacto clínico utilizando dos niveles de corte.

Debido a que el diagnóstico de NAVM por métodos cualitativos otorga la misma sobrevida que un enfoque cuantitativo, este consenso ha decidido que quede a criterio institucional si se aplican dos niveles de corte o si se aplica uno solo como en el grueso de la literatura científica. 3C

La propuesta de los dos niveles de corte deja necesariamente una zona intermedia en la que el grupo de médicos tratantes pueden optar por mantener el tratamiento, suspender su aplicación o buscar otras causas, de acuerdo a la evaluación y condición de cada caso.

Informar periódicamente la distribución de la resistencia antimicrobiana. El análisis de la resistencia antimicrobiana observada en una unidad de tiempo determinada es fundamental y determinante para el diseño adecuado de pautas empíricas de tratamiento. Si esta información no está disponible, los esquemas terapéuticos utilizados durante los primeros días podrían no tener una cobertura adecuada y así disminuir las posibilidades de sobrevida del paciente.

Se recomienda un análisis de la distribución de las especies bacterianas involucradas y de los patrones de resistencia para la unidad de hospitalización respectiva. Informes globales conteniendo los datos generales del hospital son de baja utilidad debido a variaciones en los perfiles de resistencia y a la concentración de ellas en uni- 
dades críticas ${ }^{98}$. El informe debe señalar específicamente los resultados observados frente a aislados de $P$. aeruginosa, A. baumannii, $S$. aureus y de las enterobacterias predominantes en el período ${ }^{99}$.

La periodicidad de estos informes debe ser establecida en conjunto con los médicos clínicos de las unidades críticas para apoyar adecuadamente el diseño de los tratamientos empíricos iniciales. A1.

Advertir sobre las limitaciones de esta estrategia. El diagnóstico cuantitativo de NAVM está limitado por cambios recientes en la terapia antimicrobiana, por el uso de puntos de corte con una sensibilidad y especificidad no ideal y por su aplicación restringida hacia ciertas etiologías bacterianas ${ }^{100}$. El estudio rutinario de levaduras tiene el inconveniente de que infrecuentemente un recuento significativo para este tipo de agentes se asocia a evidencia histológica de neumonía por estos microorganismos ${ }^{101}$. La detección de agentes nosocomiales atípicos como Legionella spp, o agentes virales, estos últimos especialmente importantes en la población pediátrica, debe ser solicitada en forma complementaria. En pacientes inmunocomprometidos los estudios cuantitativos deben ser solicitados junto a otras alternativas de diagnóstico.

Indicaciones de cultivo en pacientes con sospecha de NAVM. Se recomienda realizar cultivo simple o cuantitativo de AET a todo paciente con sospecha de NAVM (conexión a VM $>48$ hrs y presencia de criterios clínicos-radiológicos) y en el cual no se hayan efectuado cambios de tratamiento antimicrobiano durante las últimas $72 \mathrm{hrs}$. La existencia de criterios clínicos y radiológicos es fundamental para plantear la sospecha de NAVM y de esta manera, no caer en un sobrediagnóstico basado solamente en cultivos con recuentos altos, lo que expone al paciente a tratamientos innecesarios.

\section{Microorganismos patógenos en NAVM}

No todas las bacterias identificadas en el estudio de la vía aérea tienen el mismo rol patogénico en el caso de NAVM. Algunos de estos agentes tienen un rol establecido, otros deben ser considerados de acuerdo al tipo de hospedero y algunos no tienen un rol aceptado a la luz de la evidencia actual ${ }^{102}$. Por otra parte, en los últimos años han emergido nuevos agentes causales como los virus ${ }^{103}$. En la Tabla 8 se presentan estos agentes causales y las recomendaciones de estudio etiológico, incorporación en el informe y el estudio de susceptibilidad correspondiente. Algunos agentes se comentan en forma específica.

Moraxella catarrhalis y Haemophilus influenzae. Estos agentes se asocian a pacientes con enfermedad pulmonar crónica subyacente y en quienes no ha ocurrido una presión selectiva con antimicrobianos. Por ello, típicamente se observan en pacientes que presentan NAVM poco después del ingreso ${ }^{104}$.

Stenotrophomonas maltophilia. Este agente es de baja ocurrencia, tiende a ocurrir en pacientes en ventilación mecánica por largo tiempo y luego del uso de carbapenémicos, a los cuales es resistente. Se adquiere habitualmente de fuentes exógenas. Se asocia a una elevada mortalidad más por las condiciones del hospedero afectado que por la virulencia del agente. En ocasiones, su rol se complica en el análisis debido a la co-existencia de otros agentes. Se debe discriminar la colonización de la infección y, a diferencia de lo que ocurre en $P$. aeruginosa, la colonización es transitoria, incluso sin tratamiento específico $^{102,104,105}$.

Aspergillus sp. Este género fúngico ha cobrando importancia progresiva por la incorporación de pacientes inmunocomprometidos a la UCI, con cifras que pueden superar el $10 \%$ de los ingresos y porque se ha descrito como agente patogénico en grupos independientes a los tradicionales episodios de neutropenia febril. Estos grupos incluyen actualmente a pacientes con enfermedad pulmonar obstructiva crónica, con cirrosis hepática o usuarios de corticoesteroides. En estos pacientes no tradicionales en UCI, la TAC no demuestra los clásicos signos del halo o la crescente, sino que formas nodulares o cavitadas. El diagnóstico por detección de galactomanano en LBA ofrece una sensibilidad similar (80vs $78 \%$ ) pero una mejor especificidad que la detección en suero (93 vs 74\%). En la serie comentada, documentada en la mayor parte de los casos con autopsias, se observó una tasa cercana a $10 \%$ de falsos positivos por uso concomitante de piperacilina/ tazobactam $^{106}$.

Herpesvirus simplex tipo 1. Este agente viral ha sido investigado progresivamente en los últimos años. Los primeros estudios indicaban que el aislamiento de VHS-1 en pacientes en VM era frecuente, superando en algunos estudios el $60 \%$ en la vía aérea inferior y que su presencia se asociaba a mayor duración de VM e incidencia de NAVM ${ }^{103,107}$. La detección de VHS-1 sólo parece ocurrir en pacientes con serología IgG positiva, indicando una reactivación, y también se asocia al uso previo de corticosteroides. Su detección seriada mediante RPC cuantitativa demuestra una curva progresiva que se inicia aproximadamente al séptimo día de intubación con incrementos de $1 \mathrm{log} / \mathrm{mL}$ al día, llega a un máximo de $10^{7}$ copias/mL a la semana siguiente, observándose luego una declinación ${ }^{107}$. La detección de VHS-1 en la vía aérea podría indicar sólo una reactivación asociada al estrés del paciente y no implicar necesariamente un rol patogénico 


\section{Grupo etiológico}

\section{Agentes etiológicos establecidos}

S. aureus susceptible a meticilina, S. pneumoniae, $H$. influenzae

Acinetobacter spp, $S$. aureus resistente a meticilina, Serratia spp

Pseudomonas spp

Agentes inusuales o emergentes
Legionella spp
Moraxella catarrhalis
Stenotrophomonas maltophilia
Aspergillus spp
Virus respiratorios
Herpes simplex 1 (VHS-1)
Agentes inusuales y no patogénicos
Staphylocococcus coagulasa negativa
Corynebacterium spp
Anaerobios

\section{Comentarios y recomendación}

Microorganismos endógenos considerados de baja mortalidad si el paciente recibe un tratamiento adecuado. Informar recuento y susceptibilidad. A2

Microorganismos exógenos, con rango variable de virulencia. Informar recuento y susceptibilidad. A2

Microorganismos exógenos o endógenos. Informar recuento y susceptibilidad. A2

Solicitar estudio en brotes de NAVM sin agente. Detectar por antígeno urinario. A2

Se considera patógeno actualmente. Informar recuento y presencia de $\beta$-lactamasa por test rápido (cefinasa). B2

Informar con recuento y antibiograma. B2

Generalmente contaminante o colonizante en NAVM. Descrito como agente en pacientes con corticoesteroides, cirrosis y EPOC además de los tradicionales pacientes neutropénicos. Sólo informar si se aisla en forma repetida como agente único. B3

Estudiar en presencia de brotes nosocomiales y/o comunitarios. Utilizar inmunofluorescencia, inmunocromatografía o RPC. A2

Agente emergente de NAVM. Hasta 21\% de NAVM asociados a VHS-1 con aumento de días de VM, nuevos eventos de NAVM y prolongación de la estadía. Sin recomendación específica actual para su detección. Considerar su estudio en forma de protocolos. B2

Para este grupo de agentes que se detalla a continuación, sólo informar si se aislan en forma repetida, como agente único y en recuento alto. B3

Considerado sin rol patogénico.

Comensal, excepcionalmente descrito como agente en infección mixta con anaerobios

Integrante de infecciones mixtas, no se demuestra rol específico en NAVM

Comensal

Comensal. Evidencia histopatológica como agente etiológico de NAVM en pacientes inmunosuprimidos

No se considera patógeno. Factor de mal pronóstico, predictor de NAVM por P. aeruginosa. Informar presencia de levaduras sin recuento como comentario. B3 directo en las células o tejido pulmonar que pudiera ser atribuible a este agente. Para aclarar esta incertidumbre, Luyt y cols, desarrollaron un estudio prospectivo en pacientes no inmunosuprimidos que permitió corroborar el rol patogénico de VHS-1 en pacientes en $\mathrm{VM}^{103}$. En aproximadamente la mitad de los pacientes en quienes se sospechó una NAVM se pudo demostrar la presencia de VHS-1 en muestras oro-faríngeas o del LBA y en cerca de $40 \%$ de ellas, se encontró evidencia histológica o citológica de neumonitis viral. El promedio de estos casos ocurrió a las dos semanas de VM (5 a > 30 días). La mitad de ellos tenía una NAVM bacteriana también y el resto sólo asociada a VHS-1. Los factores de riesgo asociados a neumonitis por VHS-1 fueron la presencia de gingivoestomatitis, la detección de VHS-1 en muestras oro-faríngeas o en muestras del árbol respiratorio inferior, la detección de cuerpos de inclusión tipo A de Cowdry en las muestras y la presencia de lesiones macroscópicas en la mucosa respiratoria inferior ${ }^{103}$. No se encontraron diferencias en mortalidad pero no hubo randomización en las terapias. La carga viral de los pacientes afectados fue mayor que en aquellos sin neumonitis y se pudo establecer un nivel de corte $>8 \times 10^{4}$ copias/millón de células para predecir este evento (sensibilidad y especificidad cercanas a 80\%). Las implicancias de estos hallazgos no se pueden establecer con claridad aún, debido a la falta de estudios que aclaren el mejor método diagnóstico y el impacto terapéutico de los antivirales en estos pacientes o incluso algún rol profiláctico. Los grupos tratantes pueden considerar la detección de HSV-1 pero en forma protocolizada. B2.

Candida spp. Este grupo de levaduras no se considera patógeno en este contexto y coloniza frecuentemente la vía aérea en pacientes en VM que reciben corticosteroides o antimicrobianos. En uno de los pocos estudios que han 
logrado mostrar un rol patogénico para Candida, sólo dos de 25 pacientes no neutropénicos en VM presentaron infección confirmada por Candida sp, uno como infección pleural y otro como neumonía confirmada histológicamente ${ }^{101,108}$. En pacientes inmunosuprimidos tiene un rol infrecuente como agente de neumonía. Algunos estudios señalan que su presencia en vía aérea se asocia a un mal pronóstico, con mayor mortalidad, estadía en UCI o al desarrollo posterior de neumonía por $P$. aeruginos $a^{109}$.

\section{Diagnóstico de NAVM en pediatría}

A pesar de ser una entidad menos frecuente en niños que en adultos, la NAVM en un paciente pediátrico constituye un problema importante que debe ser enfrentado en forma adecuada, por el riesgo que representa para la vida del paciente, por el alto costo del tratamiento y por el aumento de la estadía hospitalaria.

Las limitaciones de la sospecha sobre bases clínicas y radiológicas son similares a las descritas previamente para pacientes adultos, al igual que las limitaciones derivadas del diagnóstico microbiológico mediante hemocultivos o cultivo de líquido pleural. Asimismo, la detección de ciertas etiologías virales no descarta la posibilidad de una sobreinfección bacteriana durante la VM.

En pediatría no se han desarrollado estudios que permitan seleccionar una estrategia sobre otra, de acuerdo a su impacto en el pronóstico del paciente y sólo se cuenta con algunas experiencias publicadas sobre el uso de diferentes métodos diagnósticos ${ }^{100,110,111}$. Los planteamientos señalados sobre la conveniencia del diagnóstico microbiológico de la NAVM en pacientes adultos son igualmente recomendables y aplicables en pacientes pediátricos: descartar el diagnóstico de NAVM permitiendo el estudio de causas alternativas, diseñar pautas empíricas iniciales de tratamiento con la información reunida y ajustar la terapia antimicrobiana. Esta estrategia permite efectuar además, el diagnóstico de sobreinfección bacteriana en aquellos casos con bronconeumonía viral.

El diagnóstico microbiológico de la NAVM en pacientes pediátricos ha sido escasamente estudiado y no existe actualmente información sobre el impacto en el pronóstico de diferentes técnicas o sobre la utilización de métodos de referencia histológicos que justifiquen una determinada técnica sobre otra. En pacientes menores es difícil realizar estudios broncoscópicos (invasores) por el reducido diámetro del tubo endotraqueal. Por otra parte, la disponibilidad de recursos humanos y de los equipos involucrados en el diagnóstico mediante procedimientos invasores, es más limitada que la existente para pacientes adultos en nuestro país. Estas consideraciones hacen recomendable la utilización de un método diagnóstico no invasor en casos pediátricos de NAVM. Tanto el cultivo simple, el cultivo cuantitativo del AET, como minilavados broncoalveolares a ciegas (mini-LBA) han sido reportados en pacientes pediátrico ${ }^{100,110-113}$. En un estudio utilizando como patrón de referencia un panel de expertos, Gauvin y cols. compararon la sensibilidad y especificidad de los criterios del CDC, mini-LBA a ciegas (sin fibrobroncoscopia) con recuento cuantitativo, el índice bacteriano (suma de los exponentes de los recuentos de diferentes bacterias), recuento de bacterias intracelulares y el cultivo simple del aspirado endotraqueal ${ }^{110,11}$. Los autores reportaron que la estrategia de mejor sensibilidad y especificidad es un índice bacteriano $>5$ obtenido a través de un mini LBA a ciegas, con cultivo cuantitativo. La sensibilidad reportada fue de $78 \%$ y su especificidad $86 \%$. Sin embargo, el diseño de este estudio es cuestionable por el tipo de patrón de referencia utilizado. Como era de esperar, el cultivo simple fue muy sensible (100\%) pero inespecífico (40\%) y los otros métodos tampoco tuvieron buen desempeño. ${ }^{111}$

En un estudio de un mejor diseño, incorporando un estándar de oro de tipo compuesto, en algunos casos con confirmación histológica, Labenne y cols, reportaron puntos de corte similares para el mini-LBA y para la técnica de $\mathrm{CP}$ a ciegas (sin fibrobroncoscopio) que los utilizados en adultos $\left(>10^{4} \mathrm{ufc} / \mathrm{mL}\right.$ y $>10^{3} \mathrm{ufc} / \mathrm{mL}$, respectivamente $)^{100}$. La sensibilidad del mini-LBA a ciegas fue de $72 \%$ y su especificidad $88 \%$. En el caso de la técnica del CP, la sensibilidad resultó similar (69\%) y su especificidad mayor (95\%). El rendimiento diagnóstico se incrementó utilizando la información combinada de las técnicas descritas junto al recuento de bacterias intracelulares $>1 \%$ (sensibilidad 90\%, especificidad $88 \%$ ). Se observaron complicaciones menores como sangrado transitorio $(11 \%)$, fiebre $(6 \%)$ o requerimientos de mayor oxigenación transitorios $(10 \%)$. La tasa de complicaciones mayores fue baja con tres casos de neumotórax entre los 103 niños analizados, dos de estos casos fueron de resolución espontánea.

Estos antecedentes demuestran que, a pesar de que no existe mucha información publicada en pediatría y que hay pocos estudios con confirmación histológica, en ellos se han aplicado fundamentalmente métodos no invasores (mini-LBA a ciegas o $\mathrm{CP}$ a ciegas) con cultivos simples o cuantitativos. Las sensibilidades y especificidades observadas y puntos de corte son similares a los descritos en pacientes adultos. Por ello, las mismas estrategias aplicadas en adultos pueden ser recomendadas para pacientes pediátricos, aunque el cultivo cuantitativo de aspirado endotraqueal no ha sido, en general, evaluado en esta población. B2.

Los criterios diagnósticos propuestos por el CDC para el reconocimiento de NAVM en pediatría, que se estratifican por edad, están diseñados para la identificación de casos de neumonía adquirida en el hospital y no específicamente para NAVM ${ }^{114}$. Además, han sido criticados por algunos autores ${ }^{115}$. Los reparos incluyen las dificultades 
para incluir ciertos valores de temperatura como criterio clínico cuando por prácticas institucionales se evita el ascenso de la temperatura en forma sistemática, y la subjetividad y variabilidad en la evaluación de la cantidad de secreción bronquial, trabajo respiratorio o auscultación, parámetros que pueden variar por la humidificación de la vía aérea, la frecuencia de aspiraciones o instilaciones salinas. También, se cuestiona las dificultades para evaluar el trabajo respiratorio, la taquipnea o la apnea en pacientes sedados ${ }^{115}$. Finalmente, los criterios del CDC para neumonía nosocomial en pediatría no incorporan estudios microbiológicos.

Diferentes agentes virales, tales como el virus influenza, virus respiratorio sincicial y adenovirus pueden ocasionar brotes o casos esporádicos nosocomiales de NAVM en pacientes pediátricos ${ }^{116,117}$. El estudio de esta posibilidad debe ser realizado por técnicas de inmunofluorescencia en el AET e idealmente mediante cultivo viral específico. La detección de adenovirus mediante inmunofluorescencia es limitada y debe ser acompañada por métodos complementarios ${ }^{118}$.

\section{Resumen ejecutivo}

Recomendaciones para el diagnóstico de neumonía y traqueo-bronquitis asociadas a ventilación mecánica (NAVM y TAVM)

Estrategia microbiológica. Se recomienda el uso de estrategias que permitan contar con información microbiológica para el diagnóstico de NAVM. Ello permite disponer de datos epidemiológicos relevantes para el diseño de esquemas empíricos iniciales apropiados para los casos futuros y para ajustar el esquema en un paciente dado. A1

Se debe enfatizar que el uso de criterios microbiológicos debe ir acoplado a la sospecha clínica y radiológica de NAVM y no reducir el caso a la simple solicitud de cultivos.

El estudio microbiológico debe ser solicitado antes del cambio de antimicrobianos. (En la Tabla 8 se entregan recomendaciones específicas sobre el informe para microorganismos patógenos conocidos, inusuales o emergentes)

Métodos no invasores. Utilizar una estrategia diagnóstica no invasora por su facilidad operativa, menor costo, independencia de equipos de altos costo, disponibilidad continua e impacto similar respecto a la sobrevida de los pacientes, que las estrategias invasoras. A1

Técnicas cuantitativas o cualitativas. Ambos enfoques, el cultivo simple o el cultivo cuantitativo, tienen un impacto similar en la sobrevida de los pacientes y queda a decisión institucional el uso de una u otra alternativa. A1 Sin embargo, se reconoce que la estrategia cuantitativa tiene una mayor especificidad y potenciales ventajas secundarias aún no validadas, tales como disminuir el consumo de antimicrobianos y redirigir oportunamente el estudio hacia otras causas en casos con recuentos bajos. C3

En caso de optar por una estrategia cuantitativa, queda a criterio institucional el informar uno o dos puntos de corte, ya que a la fecha no se han desarrollado estudios que hayan evaluado el impacto clínico utilizando dos niveles de corte
Informes periódicos de resistencia. La información microbiológica reunida debe ser tabulada periódicamente para facilitar el diseño de esquemas terapéuticos empíricos iniciales y para monitorizar los cambios de la resistencia antimicrobiana en el tiempo. Este aspecto es fundamental, debido a que las modificaciones terapéuticas efectuadas una vez que se recibe el informe, no tienen mayor impacto en la sobrevida del paciente, en contraste con el impacto de una cobertura antimicrobiana adecuada al inicio del evento. A1

Limitaciones. Es importante difundir las limitaciones de esta modalidad diagnóstica, la que está restringida por el uso reciente de antimicrobianos, por una sensibilidad y especificidad limitada, y por estar enfocada sólo hacia algunas etiologías bacterianas. El diagnóstico bacteriológico de NAVM no excluye la realización de otros estudios tales como aquellos referidos al reconocimiento de ciertos agentes virales o bacterianos atípicos, los que pueden ser especialmente importantes en pacientes inmunocomprometidos o pediátricos

Bio-marcadores. No se recomienda el uso rutinario de biomarcadores para el reconocimiento de NAVM ya que no ofrecen un rendimiento diagnóstico adecuado. D2

No obstante, el uso de determinaciones seriadas de procalcitonina ha permitido apoyar interrupciones en el tratamiento antimicrobiano y podría ser considerada por cada institución. B2 El uso de proteína $\mathrm{C}$ reactiva tiene un menor rendimiento diagnóstico para el estudio o seguimiento de pacientes sépticos respecto a la procalcitonina. $\mathbf{E 2}$

Traqueo-bronquitis asociada a VM. Se recomienda, discriminar la NAVM de la TAVM desde el punto de vista diagnóstico para optimizar el reconocimiento de casos verdaderos de NAVM y potencialmente seleccionar pacientes para el tratamiento de esta nueva condición. B1

NAVM en pediatría. Existe escasa experiencia publicada sobre estudios diagnósticos en pacientes pediátricos. En ellos, se han aplicado fundamentalmente métodos no invasores (mini-LBA a ciegas o $\mathrm{CP}$ a ciegas) con cultivos simples o cuantitativos. En las metodologías cuantitativas, las sensibilidades y especificidades observadas y puntos de corte son similares a los descritos en pacientes adultos. Por ello, las mismas estrategias aplicadas en adultos pueden ser recomendadas para pacientes pediátricos, aunque el cultivo cuantitativo de aspirado endotraqueal no ha sido en general evaluado en esta población. B2

NAVM: neumonía asociada a ventilación mecánica.

TAVM: traqueo-bronquitis asociada a ventilación mecánica. LBA: lavado broncoalveolar.

CP: cepillo protegido.

\section{Resumen}

La estrategia óptima para diagnosticar pacientes con neumonía asociada a ventilación mecánica (NAVM), aún no ha sido definida y es necesario revisar periódicamente nueva evidencia acumulada. Se presenta en este documento una actualización del consenso desarrollado el 2001 sobre diagnóstico de NAVM organizado por la Sociedad Chilena de Infectología. Las principales recomendaciones actuales son: incorporar una estrategia basada en un enfoque microbiológico, cuando exista sospecha de NAVM, para recolectar datos epidemiológicos y así diseñar esquemas antimicrobianos apropiados 
para los futuros casos, y aplicar sistemas no invasores de estudio, los que facilitan su acceso y permiten reducir costos. Debido a que no existen ventajas en la sobrevida de los pacientes cuando se escogen estrategias de cultivos cuantitativos sobre los no cuantitativos, no se puede recomendar una modalidad sobre la otra. Sin embargo, los cultivos cuantitativos son más específicos y facilitan descartar el diagnóstico, buscar otras alternativas y evitar el uso innecesario de antimicrobianos. No se recomienda el uso de bio-marcadores para apoyar el diagnóstico de NAVM debido a su bajo rendimiento. No obstante, el uso de determinaciones seriadas de procalcitonina ha sido útil para limitar el consumo de antimicrobianos en pacientes críticos y tiene un mejor rendimiento diagnóstico respecto a la proteína $\mathrm{C}$ reactiva. El consenso recomienda también discriminar los casos de traqueo-bronquitis asociada a $\mathrm{VM}$ que representa una entidad separada con un proceso inflamatorio, incluyendo secreciones purulentas pero sin nuevos infiltrados radiológicos. Aunque la información disponible apoya el beneficio de los antimicrobianos para tratar esta última condición, la evidencia es todavía parcial y ambas condiciones deben ser entendidas por separado.

\section{Referencias}

1.- Arancibia F, Fica A, Hervé B, Ruiz M, Yungue M. Diagnóstico de neumonía asociada a ventilación mecánica. Rev Chil Infectol 2001; 18 (suppl 2): 41-57.

2.- Hernández G, Dalmazzo R, De la Cerda G, Saavedra C, Calvo M. Prevención de la neumonía asociada a ventilación mecánica. Rev Chil Infectol 2001; 18 (Supl. 2): 66-76.

3.- Álvarez A M, Bavestrello L, Labarca J, Calvo M. Tratamiento de la neumonía asociada a ventilación mecánica. Rev Chil Infectol 2001; 18 (suppl 2): 58-65.

4.- Santolaya M E, Rabagliati R, Bidart T, Payá E, Guzmán A M, Morales R, et al. Consenso: manejo racional del paciente con cáncer, neutropenia y fiebre. Rev Chil Infectol 2005; 22 (Supl. 2): 79-113.

5.- Torres A, El-Ebiary M. Diagnostic approaches and hospital-acquired pneumonia. Sem Respir Crit Care Med 1997; 18: 149-61

6.- Kollef M H. What is ventilator-associated pneumonia and why it is important? Respir Care 2005; 50: 714-21.

7.- Fagon J Y, Chastre J, Hance A J, Montravers P, Novara A, Gibert C. Nosocomial pneumonia in ventilated patients: a cohort study evaluating attributable mortality and hospital stay. Am J Med 1993; 94: 281-8.

8.- Luna C M, Vujacich P, Niederman M S, Vay C, Gherardi C, Matera J, et al. Impact of BAL data on the therapy and outcome of ventilator-associated pneumonia. Chest 1997; 111: 676-85.

9.- Rello J, Gallego M, Mariscal D, Soñora R, Valles $\mathrm{J}$. The value of routine microbial investigation in ventilator-associated pneumonia. Am J Respir Crit Care Med 1997; 156: $196-200$

10.- Kollef M H, Bock K R, Richards R D, Hearns M L. The safety and diagnostic accuracy of minibronchoalveolar lavage in patients with suspected ventilator-associated pneumonia. Ann Intern Med 1995; 122: 743-8.

11.- Johanson W G, Pierce A K, Sanford J P,
Thomas G D. Nosocomial respiratory infection with gram negative bacilli: the significance of colonization of respiratory tract. Ann Intern Med 1972; 77: 701-6.

12.- Meduri G U, Mauldin G L, Wunderick R G, Leeper K V Jr, Jones C B, Tolley E, et al. Causes of fever and pulmonary densities in patients with clinical manifestations of ventilator associated-pneumonia. Chest 1994; 106: 221-35.

13.- Fabregas N, Ewig S, Torres A, El-Ebiary M, Ramírez J, Puig de la Bellacasa J, et al. Clinical diagnosis of ventilator-associated pneumonia revisited: comparative evaluation using immediate postmortem biopsies. Thorax 1999; 54: 867-73.

14.- Wunderink R G. Clinical criteria in the diagnosis of ventilator-associated pneumonia. Chest 2000; 117: 191S-4S

15.- Fagon J Y, Chastre J, Hance A J, Domart Y, Trouillet J L, Gilbert C. Evaluation of clinical judgment in the identification and treatment of nosocomial pneumonia in ventilated patients. Chest 1993; 103: 547-53.

16.- Lefcoe M S, Fox G A, Leasa D J, Sparrow R K, McCormack D G. Accuracy of portable chest radiography in the critical care setting. Diagnosis of pneumonia based on quantitative cultures obtained from protected brush catheter. Chest 1994; 105: 885-7.

17.- Wunderink R G, Woldenberg L S, Zeiss J, Day C M, Ciemins J, Lacher D A. The radiologic diagnosis of autopsy-proven ventilator-associated pneumonia. Chest 1992; 101: 458-63.

18.- Helling T S, Van Way C III, Krantz S, Betram K, Stewart A. The value of clinical judgment in the diagnosis of pneumonia. Am J Surg 1996; 171: 570-5.

19.- Winer-Muram HAT, Rubin S A, Ellis J V, Jennings S G, Arheat K L, Wunderink R G, et al. Pneumonia and ARDS in patients receiving mechanical ventilation: diagnostic accuracy of chest radiography. Radiology 1993; 188: 479-85

20.- Andrews C P, Coalson I J, Smith J D,
Johanson W G. Diagnosis of nosocomial pneumonia in acute diffuse lung injury. Chest 1981; 80: 254-8.

21.- Pugin J, Auckenthaler R, Mili N, Janssens J P, Lew P D, Suter P M. Diagnosis of ventilatorassociated peumonia by bacteriologic analysis of bronchoscopic and nonbronchoscopic blind bronchoalveolar lavage fluid. Am Rev Respir Dis 1991; 143: 1121-9.

22.- Papazian L, Thomas P, Garbe L, Guignon I, Thirion X, Charrel J, et al. Bronchoscopic or blind sampling techniques for the diagnosis of ventilator-associated pneumonia. Am J Respir Crit Care Med 1995; 152: 1982-91.

23.- Klompas M. Does this patient have ventilatorassociated pneumonia? JAMA 2007; 297: 158393.

24.- Rello J, Ausina V, Ricart M, Puzo C, Quintana E, Net A, et al. Risk factors for infections by Pseudomonas aeruginosa in patients with ventilator-associated pneumonia. Intensive Care Med 1994; 20:193-8.

25.- Kollef M H, Silver P, Murphy D M, Trovillion E. The effect of late-onset ventilatorassociated pneumonia in determining patient mortality. Chest 1995; 108: 1655-62.

26.- Fagon J Y, Chastre J, Hance A J, Guiguet M, Trouillet J L, Domart Y, et al. Detection of nosocomial lung infection in ventilated patients. Use of a protected specimen brush and quantitative culture techniques in 147 patients. Am Rev Respir Dis 1988; 138: 110-6.

27.- Torres A, Puig de la Bellacasa J, Xaubet A, González J, Rodríguez-Roisin R, Jiménez de Anta MT, et al. Diagnostic value of quantitative cultures of bronchoalveolar lavage and telescoping plugged catheters in mechanically ventilated patients with bacterial pneumonia. Am Rev Respir Dis 1989; 140: 306-10.

28.- Marquette C H, Herengt F, Saulnier R, Neviere R, Mathieu D, Courcol R, et al. Protected specimen brush in the assessment of ventilator-associated pneumonia. Selection of a certain lung segment for bronchoscopic sampling is unnecessary. Chest 1993; 103: 243-7. 
29.- El-Ebiary M, Torres A, González J, Puig de la Bellacasa J, García C, Jiménez de Anta MT, et al. Quantitative cultures of endotracheal aspirates for the diagnosis of ventilatorassociated pneumonia. Am Rev Respir Dis 1993; 148: 1552-7.

30.- Torres A, El-Ebiary M, Padró L, González J, de la Bellacasa J P, Ramírez J, et al. Validation of different techniques for the diagnosis of ventilator-associated pneumonia. Comparison with immediate post mortem pulmonary biopsy. Am J Respir Crit Care Med 1994; 149: 324-31.

31.- Chastre J, Viau F, Brun P, Pierre J, Dauge M C, Bouchama A, et al. Prospective evaluation of the protected specimen brush for the diagnosis of pulmonary infections in ventilated patients. Am Rev Respir Dis 1984; 130: 924-9.

32.- Baughman R P, Thorpe J E, Staneck J, Rashkin M, Frame P T. Use of the protected specimen brush in patients with endotracheal or tracheostomy tubes. Chest 1987; 91: 233-6.

33.- Chastre J, Fagon J Y, Soler P, Bornet M, Domart Y, Trouillet J L, et al. Diagnosis of nosocomial bacterial pneumonia in intubated patients undergoing ventilation: Comparison of the usefulness of bronchoalveolar lavage and the protected specimen brush. Am J Med 1988; 85: 499-506.

34.- Fagon J Y, Chastre J, Domart Y, Trouillet J L, Pierre J, Darne C, et al. Nosocomial pneumonia in patients receiving continuous mechanical ventilation: Prospective analysis of 52 episodes with use of a protected specimen brush and quantitative cultures techniques. Am Rev Respir Dis 1989; 139: 877-84.

35.- Pham LH, Brun-Boisson C, Legrand P, Rauss A, Verra F, Brochard L, et al. Diagnosis of nosocomial pneumonia in mechanically ventilated patients. Comparison of a plugged telescoping catheter with protected specimen brush. Am Rev Respir Dis 1991; 143: 1055-61.

36.- De Castro F R, Violan S J, Capuz B L, Luna JC, Rodríguez B G, Alonso J L. Reliability of the protected catheter brush in the diagnosis of pneumonia in mechanically ventilated patients. Crit Care Med 1991; 19: 171-5.

37.- Sole-Violan J, Rodríguez de Castro F, Rey A, Freixinet J, Aranda A, Caminero J, et al. Comparison of bronchoscopic diagnostic techniques with histological findings in brain dead organ donors without suspected pneumonia. Thorax 1996; 51: 929-31.

38.- Timsit J F, Misset B, Goldstein F W, Vaury P, Carlet J. Reappraisal of distal diagnostic testing in the diagnosis of ICU-acquired pneumonia. Chest 1995; 108: 1632-9.

39.- Villers D, Derrienic D, Raffi F, Germaud P, Baron D, Nicolas F, et al. Reliability of bronchoscopic protected catheter brush in intubated and ventilated patients. Chest 1985; 88: 527-30

40.- Marquette C H, Copin M C, Wallet F,
Neviere R, Saulnier F, Mathieu D, et al. Diagnostic test for pneumonia in ventilated patients: Prospective evaluation of diagnostic accuracy using histology as a diagnostic gold standard. Am J Respir Crit Care Med 1995; 151 : 1878-88.

41.- Chastre J, Fagon J Y, Bornet-Lesco M, Calvat S, Dombret M C, al Khani R, et al. Evaluation of bronchoscopic techniques for the diagnosis of nosocomial pneumonia. Am J Respir Crit Care Med 1995; 152: 231-40.

42.- Cook D, Fitzgerald J M, Guvatt G H, Walter S Evaluation of the protected brush catheter and bronchoalveolar lavage in the diagnosis of nosocomial pneumonia. J Intensive Care Med 1991; 6: 196-205.

43.- Marquette C H, Georges H, Wallet F, Ramon P, Saulnier F, Neviere R, et al. Diagnostic efficiency of endotracheal aspirates with quantitative bacterial cultures in intubated patients with suspected pneumonia. Comparison with the protected specimen brush. Am Rev Respir 1993; 148: 138-44.

44.- Rodríguez de Castro F, Sole J, Elcuaz R. Quantitative cultures of protected brush specimen and bronchoalveolar lavage in ventilated patients without pneumonia. Am J Respir Crit Care Med 1994; 149: 320-3.

45.- Torres A, Martos A, Puig de la Bellacasa J P, Ferrer M, el-Ebiary M, González J, et al. Specificity of endotracheal aspirate aspiration, protected specimen brush and bronchoalveolar lavage in mechanically ventilated patients. Am Rev Resp Dis 1993; 147: 952-7.

46.- Timsit J F, Misset B, Renaud B, Goldstein F W, Carlet J. Effect of previous antimicrobial therapy on the accuracy of the main procedures used to diagnose nosocomial pneumonia in patients who are using ventilation. Chest 1995; 108: 1036-40.

47.- Dreyfuss D, Mier L, Le Bourdelles K, Djedaini K, Brun P, Boussougant Y, et al. Clinical significance of borderline quantitative protected brush specimen culture results. Am Rev Respir Dis 1993; 147: 941-51.

48.- Flanagan P G, Findlay G P, Magee J T, Ionescu A, Barnes R A, Smithies M. The diagnosis of ventilator-associated pneumonia using non-bronchoscopic, non-directed lung lavages. Intensive Care Med. 2000; 26: 20-30.

49.- Jourdain B, Novara A, Joly-Guillou M L, Dombret M C, Calvat S, Trouillet J L, et al. Role of quantitative cultures of endotracheal aspirates in the diagnosis of nosocomial pneumonia. Am J Respir Crit Care Med 1995; 152: 241-6.

50.- San Pedro G. Are quantitative cultures useful in the diagnosis of hospital-acquired pneumonia? Chest 2001; 119: 385S- 390S

51.- Berger R, Arango L. Etiologic diagnosis of bacterial nosocomial pneumonia in seriously ill patients. Crit Care Med 1985; 13: 833-6.
52.- Hill J, Ratliff Parrot J C W, Lamy M, Falla R J, Koeniger E. Pulmonary pathology in acute respiratory insufficiency: Lung biopsy as a diagnostic tool. J Thorac Cardiovasc Surg 1976; 71: 64-71.

53.- Marquette C H, Wallet F, Copin M C. Bronchoscopic invasive diagnostic techniques for the diagnosis of pneumonia. Eur Respir Mon 1997; 3: 175-88.

54.- Bregeon F, Papazian L, Thomas P, Carret V, Garbe L, Saux P, et al. Diagnostic accuracy of protected catheter sampling in ventilatorassociated bacterial pneumonia. Eur Respir J 2000; 16: 969-75.

55.- Torres A, El-Ebiary M, Fàbregas N, González J, de la Bellacasa J P, Hernández C, et al. Value of intracellular bacteria detection in the diagnosis of ventilator-associated pneumonia. Thorax 1996; 51: 378-84.

56.- Meduri G U, Beals D H, Maijub A G, Baselski V. Protected bronchoalveolar lavage. A new bronchoscopic technique to retrieve uncontamined distal airways secretions. Am Rev Respir Dis 1991; 143: 855-64.

57.- Corley D E, Kirtland S H, Winterbauer R H, Hammar S P, Dail D H, Bauermeister D E, et al. Reproducibility of the histologic diagnosis of pneumonia among a panel of four pathologists. Chest 1997; 112: 458-65

58.- Torres A, De la Bellacasa J, Rodríguez-Roisin R, Jiménez de Anta M T, Agusti-Vidal A, et al. Diagnostic Value of telescoping plugged catheters in mechanically ventilated patients with bacterial pneumonia using the metras catheter. Am Rev Respir Dis 1988; 138: 117-20.

59.- Rouby J J, Rossignon M D, Nicolas M H, Martin de Lassale E, Cristin S, Grosset J, et al. A prospective study of protected bronchoalveolar lavage in the diagnosis of nosocomial pneumonia. Anesthesiology 1989; 71: 679-85

60.- Ruiz M, Torres A, Ewig S, Marcos MA, Alcón A, Lledo R, et al. Noninvasive versus invasive microbial investigation in ventilatorassociated pneumona. Evaluation of outcome. Am J Resp Crit Care Med 2000; 162: 119-25.

61.- Blasi F, Cosentini R. Noninvasive methods for the diagnosis of pneumonia. Eur Respir Mon 1997; 3: 157-74.

62.- Sánchez Nieto JM, Seller Pérez G, Carrillo Alcaraz A, Ruiz Gómez J, Sola Pérez J, Egea Caparrós JM, et al. Comparative study of protected alveolar lavage versus occluded telescopic catheter in patients with suspected pneumonia and under mechanic ventilation. Med Clin (Barc) 1993; 100: 1-4.

63.- Solé-Violán J, Rodríguez de Castro F, Rey A, Martin-González JC, Cabrera-Navarro P. Usefulness of microscopic examination of intracellular organism in lavage fluid in ventilator-associated pneumonia. Chest 1994; 106: 889-94. 
64.- Aubas S, Aubas P, Capdevila X, Darbas H, Roustan J, Cailar J. Bronchoalveolar lavage for diagnosis bacterial pneumonia in mechanically ventilated patients. Am J Respir Crit Care Med 1994; 149: 860-6.

65.- Vellés J, Rello J, Fernández R, Blanch L, Baigorri F, Mestre J, et al. Role of bronchoalveolar lavage in mechanically ventilated with suspected pneumonia. Eur J Clin Microbiol Infect Dis 1994; 13: 549-58.

66.- Hospital-acquired pneumonia in adults: diagnosis, assessment of severity, initial antimicrobial therapy, and preventative strategies: A consensus statement. Am J Respir Crit Care Med 1996; 153: 1711-25.

67.- Celis R, Torres A, Gatell J M, Almela M, Rodríguez-Roisin R, Agusti-Vidal A. Nosocomial pneumonia. A multivariate analysis of risk and prognosis. Chest 1988; 93: 318-24.

68.- Alvarez-Lerma F, and the ICU-acquired pneumonia study group. Modification of empiric antibiotic treatment in patients with pneumonia acquired in the intensive care unit. Intensive Care Med 1996; 22: 387-94.

69.- Kollef MH, Ward S. The influence of mini-BAL cultures on patient outcomes. Implications for the antibiotic management of ventilator associated pneumonia. Chest 1998; 113: 412-20.

70.- Sánchez-Nieto J M, Torres A, García-Cordiba F, El-Ebiary M, Carillo A, Ruiz M, et al. Impact of invasive and non invasive quantitative cultures sampling on outcome of ventilator-associated pneumonia: A pilot study. Am J Respir Crit Care Med 1998; 157: 371-6.

71.- Fagon J, Chastre J, Wolff M, Gervais C, Parer-Aubas S, Stephan F, et al. Invasive and noninvasive strategies for management of suspected ventilator-associated pneumonia. Ann Intern Med 2000; 132: 621-30.

72.- Sole-Violan J, Arroyo-Fernández J, Bordes-Benítez A, Cardeñosa-Cendrero JA, Rodríguez de Castro F. Impact of quantitative invasive diagnostic techniques in the management and outcome of mechanically ventilated patients with suspected pneumonia. Crit Care Med 2000; 28: 2737-41.

73.- Canadian Critical Care Trials Group. A randomized trial of diagnostic techniques for ventilator-associated pneumonia. N Engl J Med 2006; 355: 2619-30.

74.- Kwon Y, Milbrandt ET, Yende S. Diagnostic techniques for ventilator-associated pneumonia: conflicting results from two trials. Crit Care 2009:13 (DOI: 10.1186/cc7797).

75.- Shorr A F, Sherner J H, Jackson W L, Kollef M H. Invasive approaches to the diagnosis of ventilator-associated pneumonia: a meta-analysis. Crit Care Med 2005; 33: 46-53.

76.- Bonten M J, Bergmans D C, Stobbering E E, van der Geest S, De Leeuw P W, van Tiel F H, et al. Implementation of bronchoscopic techniques in the diagnosis of ventilator- associated pneumonia to reduce antibiotic use. Am J Respir Crit Care Med 1997; 156: 1820-4.

77.- Heyland D K, Cook D J, Marshall J, Heule M, Guslits B, Langs J, et al. The clinical utility of invasive of invasive diagnostic techniques in the setting of ventilator-associated pneumonia. Canadian Critical Care Trials Group. Chest 1999; 115: 1076-84.

78.- Seligman R, Papassotiriou J, Morgenthaler N G, Meisner M, Teixeira P J Z. Copeptin, a novel prognostic biomarker in ventilator-associated pneumonia. Crit Care 2008; 12:R11

79.- Katan M, Müller B, Christ-Crain M. Copeptin: a new and promising diagnostic and prognostic marker. Crit Care 2008; 12: 117.

80.- Bouchon A, Dietrich J, Collona M. Cutting edge: Inflammatory responses can be triggered by TREM-1, a novel receptor expressed on neutrophils and monocytes. J Immunol 2000; 164: 4991-5.

81.- Gibot S, Cravoisy A, Levy B, Bene M C, Faure G, Bollaert P E. Soluble triggering receptor expressed on myeloid cells and the diagnosis of pneumonia. N Engl J Med 2004; 350: 451-8.

82.- Determann R M, Millo J L, Gibot S, Korevaar J C, Vroom M B, van der Poll T, et al. Serial changes in soluble triggering receptor expressed on myeloid cells in the lung during development of ventilator-associated pneumonia. Intensive Care Med 2005; 31 : 1495-1500.

83.- Horonenko G, Hoyt J C, Robbins R A, Singarajah C U, Umar A, Pattengill J S, et al. Soluble triggering receptor expressed on myeloid cell-1 is increased in patients with ventilator-associated pneumonia. Chest 2007; 132: 58-63.

84.- Bopp C, Hofer S, Bouchon A, Zimmermann J B, Martin E, Weigand M A. Soluble TREM- 1 is not suitable for distinguishing between systemic inflammatory response syndrome and sepsis survivors and nonsurvivors in the early stage of acute inflammation. Eur J Anaesthesiol 2009; 26: $504-7$

85.- Routsi C, Giamarellos-Bourboulis E J, Antonopoulou A, Kollias S, Siasiakou S, Koronaios A, et al. Does soluble triggering receptor expressed on myeloid cells-1 play any role in the pathogenesis of septic shock? Clin Exp Immunol 2005; 142: 62-7.

86.- Reinhart K, Carlet J. Procalcitonin. A new marker of severe infection and sepsis. Intensive Care Med 2000; 26: S 145.

87.- Bouhon C. A brief history of procalcitonin. Intensive Care Med 2000; 26: S 146-7.

88.- Becker K L, Snider R, Nylen E S. Procalcitonin assay in systematic inflammation, infection, and sepsis: clinical utility and limitations. Crit Care Med 2008; 36: 941-52.

89.- Tang B M P, Eslick G D, Craig J C, McLean A S. Accuracy of procalcitonin for sepsis diagnosis in critically ill patients: systematic review and meta-analysis. Lancet Infect Dis 2007; 7: 210-17.

90.- Duflo F, Debon R, Monneret G, Bienvenu J, Chassard D, Allaouchiche B. Alveolar and serum procalcitonin. Anesthesiology 2002; 96: 74-9.

91.- Uzzan B, Cohen R, Nicolas P, Cucherat M, Perret G Y. Procalcitonin as a diagnostic test for sepsis in critically ill adults and after surgery of trauma: A systematic review and meta-analysis. Crit Care Med 2006; 34: 1996-2003.

92.- Nobre V, Harbarth S, Graf J D, Rohner P, Pugin J. Use of procalcitonin to shorten antibiotic treatment duration in septic patients. Am J Respir Crit Care Med 2008; 177: 498-505.

93.- Craven D E, Chroneou A, Zias N, Hjalmarson K I. Ventilator-associated tracheobronchitis. Chest 2009; 135: 521-8.

94.- Nseir S, Di Pompeo C H, Soubrier S, Lenci H, Delour P, Onimus T, et al. Effect of ventilator-associated tracheobronchitis on outcome in patients without chronic respiratory failure: a case-control study. Crit Care 2005; 9:R238-R245 (DOI 10.1186/cc3508).

95.- Nseir S, Favory R, Jozefowicz E, Decamps F, Dewavrin F, Brunin G, et al. Antibiotic treatment for ventilator-associated tracheobronchitis: a randomized controlled, multicenter study. Crit Care 2008; 12: R62.

96.- Palmer L B, Smaldone G C, Chen J J, Baram D, Duan T, Monteforte M, et al. Aerosolized antibiotics and ventilator-associated tracheobronchitis in the intensive care unit. Crit Care Med 2008; 36: 2008-13.

97.- Baker A M, Bowton D L, Haponik E F. Decision making in nosocomial pneumonia. An analytic approach to the interpretation of quantitative bronchoscopic cultures. Chest 1995; 107: 85-95.

98.- Bryce E A, Smith J A. Focused microbiological surveillance and gram-negative beta-lactamasemediated resistance in an intensive care unit. Infect Control Hospit Epidemiol 1995; 16: $331-4$.

99.- Lynch J P. Hospital-acquired pneumonia. Chest 2001; 119: 373S-384S

100.-Labenne M, Poyart C, Rambaud C, Goldfarb B, Pron $\mathrm{B}$, Jouvet $\mathrm{P}$, et al. Blind protected specimen brush and bronchoalveolar lavage in ventilated children. Crit Care Med 1999; 27: 2537-43.

101.-El-Ebiary M, Torres A, Fabregas N, Puig de la Bellacasa J, González J, Ramírez J, et al. Significance of the isolation of Candida species from respiratory samples in critically ill, nonneutropenic patients. An immediate postmortem histologic study. Am J Respir Crit Care Med 1997; 156: 583-90

102.-Rello J, Díaz E, Rodríguez A. Etiology of ventilator-associated pneumonia. Clin Chest Med 2005; 26: 87-95 
103. Luyt C E, Combes A, Deback C, AubriotLorton MH, Nieszkowska A, Trouillet J L, et al Herpes simplex virus lung infection in patients undergoing prolonged mechanical ventilation. Am J Respir Crit Care Med 2007; 175: 935-42

104.-Chastre J, Fagon J Y. Ventilator-associated pneumonia. Am J Respir Crit Care Med 2002; 165: 867-903.

105.-Pathmanathan A, Waterer G W. Significance of positive Stenotrophomonas maltophilia culture in acute respiratory tract infection. Eur Respir J 2005; 25: 911-24.

106.-Meersseman W, Lagrou K, Maertens J, Wilmer A, Hermans G, Vanderschueren S, et al. Galactomanan in bronchoalveolar lavage fluid. A tool for diagnosing aspergillosis in intensive care unit patients. Am J Respir Crit Care Med 2008; 177: 27-34.

107.-De Vos N, Van Hoovels L, Vankeerberghen A, Van Vaerenbergh K, Boel A, Demeyer I, et al. Monitoring of herpes simplex virus in the lower respiratory tract of critically ill patients using real-time PCR: a prospective study. Clin Microbiol Infect 2009; 15: 358-63.
108.-Rello J, Esandi M E, Díaz E, Mariscal D, Gallego M, Vallés J. The role of Candida sp isolated from bronchoscopic samples in nonneutropenic patients. Chest 1998; 114: 146-9.

109.-Delisle M S, Wlliamson D R, Perreault M M, Albert M, Jiang X, Heyland D K. The clinical significance of Candida colonization of respiratory tract secretions in critically ill patients. J Crit Care 2008; 23: 11-17.

110.-Foglia E, Meier M D, Elward A. Ventilatorassociated pneumonia in neonatal and pediatric intensive care unit patients. Clin Microb Rev 2007; 20: 409-25.

111.- Gauvin F, Dassa C, Chaibou M, Proulx F, Farrell C A, Lacroix J. Ventilator-associated pneumonia in ventilated children: comparison of different diagnostic methods. Pediatr Crit Care Med 2003; 4: 437-43.

112.-Koumbourlis A, Kurland G. Nonbronchoscopic bronchoalveolar lavage in mechanically ventilated infants: technique, efficacy, and applications. Pediatric Pulm 1993; 15: 257-63.

113.-Burmester M, Mok Q. How safe is non- bronchoscopic bronchoalveolar lavage in critically ill mechanically ventilated children. Intensive Care Med 2001; 27: 716-21.

114.-Horan T C, Andrus M, Dudeck M A. CDC/ NHSN surveillance definition of health care associated infection and criteria for specific types of infections in the acute care setting. Am J Infect Control 2008; 36: 309-32.

115.--Morrow B M, Argent A C, Jeena P M, Green R J. Guidelines for the diagnosis, prevention and treatment of paediatric ventilator-associated pneumonia. S Afr Med J 2009; 99: 253-68.

116.-Wesley A G, Pather M, Tait D. Nosocomial adenovirus infection in a pediatric respiratory unit. J Hosp Infect 1993; 25: 183-90

117.-Holladay R C, Campbell G D Jr. Nosocomial viral pneumonia in the intensive care unit. Clin Chest Med 1995; 16: 121-33.

118.-Larrañaga C, Avendaño L, Palomino A, Díaz A. Diagnóstico de Infección por adenovirus y virus respiratorio sincicial en lactantes. Comparación entre aislamiento e inmunofluorescencia indirecta. Rev Chil Infect 1990; 7: 167-71. 


\section{Anexo. Protocolos de trabajo de muestras microbiológicas ante casos sospechosos de neumonía asociada a ventilación mecánica. Interpretación de resultados e informes}

\section{Toma de muestra microbiológica}

La muestra debe ser obtenida en forma estéril, utilizando un catéter de aspiración introducido por el tubo endotraqueal y conectando el otro extremo del catéter a un colector o trampa estéril apropiada. El procedimiento debe ser realizado por un profesional entrenado, el catéter debe ser introducido hasta encontrar resistencia y no se debe diluir la muestra con el fin de facilitar su recolección. Si las secreciones son espesas, se deben aplicar aspiraciones intermitentes hasta conseguir la muestra ${ }^{1}$. La muestra debe ser enviada rápidamente al laboratorio, especificando que se requiere cultivo cuantitativo o cualitativo de aspirado endotraqueal (AET).

\section{Procesamiento de la muestra}

El cultivo cuantitativo de AET no tiene un protocolo estandarizado reconocido. En este documento se indica una metodología modificada que no excluye alternativas de diseño institucional o derivadas de otras publicaciones ${ }^{1,2}$.

Para esta metodología se requiere un tubo estéril con perlas de vidrio, otro con $5 \mathrm{~mL}$ de suero fisiológico ( $\mathrm{NaCl} 9 \%$ ) estéril, agitador, micropipetas de $100 \mu \mathrm{L}$ con puntas desechables y como medios de cultivo, placa de agar sangre y McConkey. El procedimiento se señala en la Tabla 1 .

Tabla 1. Procesamiento y metodología del cultivo cuantitativo de aspiración endotraqueal

1. Diluya la muestra a la mitad, con igual volumen de solución fisiológica ( $\mathrm{NaCl}$ 9\%o) estéril (dilución 1:2)

2. Homogenice con perlas de vidrio y agitador durante 2 minutos

3. Extraiga $0,1 \mathrm{~mL}$ de muestra clínica y diluya en $9,9 \mathrm{~mL}$ de solución fisiológica, agite en vortex (dilución 1:100)

4. Siembre $100 \mu \mathrm{L}(0.1 \mathrm{~mL})$ de muestra diluida en cada placa de medio de cultivo (dilución 1:10). Disemine por medio de bagueta de vidrio doblada y deje secar

5. Incube en atmósfera aeróbica a $35^{\circ} \mathrm{C}$ hasta $72 \mathrm{hrs}$

6. Realice lectura de las placas diariamente hasta completar el período de observación. En caso de existir crecimiento bacteriano, realice el recuento respectivo considerando que una colonia equivale a $2000 \mathrm{ufc} / \mathrm{mL}$. La ausencia de crecimiento indica $<10^{3} \mathrm{ufc} / \mathrm{mL}$ y 500 o más colonias por placa señalan $\geq 10^{6} \mathrm{ufc} / \mathrm{mL}$.

7. La identificación bacteriana y el estudio de susceptibilidad deben realizarse de acuerdo a técnicas estandarizadas

La muestra puede ser sembrada además en placa de agar chocolate, para la detección adicional de Haemophilus influenzae en casos de NAVM de inicio precoz (durante los primeros 5 días de hospitalización). No se recomienda siembra en agar Saboureaud, debido a la falta de concordancia entre el recuento de levaduras y los hallazgos histológicos. El estudio de bacterias anaerobias solamente ha sido estandarizado para la técnica de cepillo protegido o catéter telescopado protegido, por lo que no es aplicable a través de esta metodología.

La tinción de Gram de la muestra tiene un rendimiento limitado ya que no permite predecir qué tipo de microorganismos tendrá un recuento significativo. Es sólo aplicable para descartar cierto tipo de agentes etiológicos ${ }^{3}$. Puede ser incorporado por cada institución, si así se estima conveniente.

\section{Informe de laboratorio}

La emisión del informe debe incluir un detalle de cada microorganismo aislado, con su recuento y antibiograma correspondiente. La presentación de los potenciales microorganismos identificados es necesaria debido a que cerca de un tercio de los casos tiene aislamientos polimicrobianos ${ }^{4}$.

\section{Interpretación de los resultados}

Los datos del informe pueden ser analizados tomando en cuenta sólo la especie con el recuento más elevado o, alternativamente, combinando las lecturas de las especies observadas. En la Tabla 2 se puede observar que a, medida que aumenta el criterio de corte, disminuye progresivamente la sensibilidad de esta estrategia y al mismo tiempo aumenta la especificidad. La aplicación de un recuento $\geq 10^{6} \mathrm{ufc} / \mathrm{mL}$ permite retener una sensibilidad razonable, similar a la asociada a recuentos más bajos y lograr paralelamente una especificidad significativa. En otras palabras, valores superiores a este recuento se asocian a NAVM en aproximadamente cuatro quintos de los casos (Valor predictor positivo: VPP $82 \%$ ) y los recuentos inferiores señalan la probable ausencia de neumonía a pesar de la sospecha (Valor predictor negativo: VPN 83\%). Una lectura sobre el nivel de corte, permite respaldar el uso de antimicrobianos en un caso sospechoso.

Por otra parte, un recuento $<10^{3} \mathrm{ufc} / \mathrm{mL}$ está asociado a una menor probabilidad de NAVM, lo que permite plantear la exclusión del diagnóstico. Esta interpretación sólo es aplicable si no se han realizado modificaciones a la antibioterapia recientemente.

La lectura de recuentos intermedios $\left(\geq 10^{3}<10^{6}\right)$ señala VPN y VPP variables que deben quedar a criterio del grupo tratante, debido a los potenciales riesgos de suspender el tratamiento a pesar de la existencia real 
Tabla 2. Porcentajes de diferentes parámetros diagnósticos para el cultivo cuantitativo de aspirado endotraqueal según diferentes puntos de corte

\begin{tabular}{|ccccc|}
\hline Punto de corte & $\begin{array}{c}\text { Sensibilidad } \\
(\%)\end{array}$ & $\begin{array}{c}\text { Especificidad } \\
(\%)\end{array}$ & $\begin{array}{c}\text { Valor predictor positivo } \\
(\%)\end{array}$ & $\begin{array}{c}\text { Valor predictor negativo } \\
(\%)\end{array}$ \\
$\geq 10^{3}$ & $80-86$ & $40-52$ & 37 & 82 \\
$\geq 10^{4}$ & $71-91$ & $48-57$ & 64 & 85 \\
$\geq 10^{5}$ & $71-91$ & $52-88$ & 65 & 86 \\
$\geq 10^{6}$ & $71-82$ & $83-86$ & 77 & 83 \\
$\geq 10^{7}$ & $43-45$ & $87-95$ & 63 \\
\hline Nota: Las diferentes referencias utilizadas explican la variabilidad para cada punto de corte (referencias 2,5-7).
\end{tabular}

de NAVM. De la misma manera, estas lecturas podrían sugerir la conveniencia de buscar causas alternativas.

\section{Sobre los estudios de susceptibilidad}

En la Tabla 3 se resumen las recomendaciones sobre el estudio de susceptibilidad de los agentes bacterianos asociados a NAVM.

Tabla 3. Recomendaciones sobre el estudio de susceptibilidad de agentes bacterianos detectados en neumonía asociada a ventilación mecánica

Utilice tablas CLSI (Clinical Laboratory Standard Institute) actualizadas en el laboratorio institucional para determinar los puntos de corte o concentración inhibitoria mínima (CIM) e informe de susceptibilidad respectivo. B3

Informe el valor de CIM en la medida que esté disponible. C3

Informe el valor de CIM ante vancomicina en S. aureus ya que no existen puntos de corte definidos por el CLSI para el método de Kirby-Bauer con este compuesto. B3

Efectúe e informe el valor de CIM ante tigeciclina en $A$. baumannii si el halo de inhibición es $>19$ mm por el método de Kirby-Bauer

Efectúe e informe el valor de CIM ante colistin en A. baumannii debido a la ausencia de puntos de corte definidos por el CLSI por el método de Kirby-Bauer en esta especie. B3

No se recomienda el estudio de la susceptibilidad ante sulbactam/ cefoperazona por el método de Kirby-Bauer ya que no existen puntos de corte definidos y los de cefoperazona no son claramente extrapolables. E3

\section{Referencias}

1.- El-Ebiary M, Torres A, González J, Puig de la Bellacasa J, García C, Jimenez de Anta MT, et al. Quantitative cultures of endotracheal aspirates for the diagnosis of ventilatorassociated pneumonia. Am Rev Respir Dis 1993; 148: 1552-7.

2.- Torres A, Martos A, Puig de la Bellacasa J P, Ferrer M, El-Ebiary M, González J, et al. Specificity of endotracheal aspirate aspiration, protected specimen brush and bronchoalveolar lavage in mechanically ventilated patients. Am Rev Respir Dis 1993; 147: 952-7.

3.- Salata R, Lederman M, Shlaes D, Jacobs M, Eckstein E, Tweardy D, et al. Diagnosis of nosocomial pneumonia in intubated, intensive care unit patients. Am Rev Respir Dis 1987; 135: 426- 32.

4.- Bryce EA, Smith J.A. Focused microbiological surveillance and gram-negative beta-lactamase-mediated resistance in an intensive care unit. Infect Control Hospit Epidemiol 1995; 16: 331-4.

5.- Marquette CH, Georges H, Wallet F, Ramon P, Saulnier F, Neviere R, et al. Diagnostic Efficiency of endotracheal aspirates with quantitative bacterial cultures in intubated patients with suspected pneumonia. Comparison with the protected specimen brush. Am Rev Respir 1993; 148: 138-44.

6.- Jourdain B, Novara A, Joly-Guillou ML, Dombret MC, Calvat S, Trouillet JL, et al. Role of quantitative cultures of endotracheal aspirates in the diagnosis of nosocomial pneumonia. Am J Respir Crit Care Med 1995; 152: 241-6.

7.- San Pedro G. Are quantitative cultures useful in the diagnosis of hospital-acquired pneumonia? Chest 2001; 119: 385S-390S. 